\title{
Comparable incidence of periprosthetic tibial fractures in cementless and cemented unicompartmental knee arthroplasty: a systematic review and meta-analysis
}

\author{
Joost A. Burger ${ }^{1} \cdot$ Tjeerd Jager $^{2} \cdot$ Matthew S. Dooley $^{1} \cdot$ Hendrik A. Zuiderbaan $^{3} \cdot$ Gino M. M. J. Kerkhoffs $^{4}$. \\ Andrew D. Pearle ${ }^{1}$
}

Received: 22 July 2020 / Accepted: 11 January 2021 / Published online: 2 February 2021

(c) The Author(s) 2021

\begin{abstract}
Purpose (I) To determine the incidence of periprosthetic tibial fractures in cemented and cementless unicompartmental knee arthroplasty (UKA) and (II) to summarize the existing evidence on characteristics and risk factors of periprosthetic fractures in UKA.

Methods Pubmed, Cochrane and Embase databases were comprehensively searched. Any clinical, laboratory or case report study describing information on proportion, characteristics or risk factors of periprosthetic tibial fractures in UKA was included. Proportion meta-analysis was performed to estimate the incidence of fractures only using data from clinical studies. Information on characteristics and risk factors was evaluated and summarized.

Results A total of 81 studies were considered to be eligible for inclusion. Based on 41 clinical studies, incidences of fractures were $1.24 \%$ (95\% CI 0.64-2.41) for cementless and 1.58\% (95\% CI 1.06-2.36) for cemented UKAs (9451 UKAs). The majority of fractures in the current literature occurred during surgery or presented within 3 months postoperatively ( 91 of $127 ; 72 \%$ ) and were non-traumatic ( 95 of $113 ; 84 \%$ ). Six different fracture types were observed in 21 available radiographs. Laboratory studies revealed that an excessive interference fit (press fit), excessive tibial bone resection, a sagittal cut too deep posteriorly and low bone mineral density (BMD) reduce the force required for a periprosthetic tibial fracture to occur. Clinical studies showed that periprosthetic tibial fractures were associated with increased body mass index and postoperative alignment angles, advanced age, decreased BMD, female gender, and a very overhanging medial tibial condyle.

Conclusion Comparable low incidences of periprosthetic tibial fractures in cementless and cemented UKA can be achieved. However, surgeons should be aware that an excessive interference fit in cementless UKAs in combination with an impaction technique may introduce an additional risk, and could therefore be less forgiving to surgical errors and patients who are at higher risk of periprosthetic tibial fractures.
\end{abstract}

Level of evidence $\mathrm{V}$.

Keywords Periprosthetic fractures $\cdot$ Tibial plateau fractures $\cdot$ Complications $\cdot$ Failure modes $\cdot$ Unicompartmental knee arthroplasty $\cdot$ Partial knee replacement $\cdot$ UKA $\cdot$ PKR

Joost A. Burger

yoostburger@gmail.com

1 Department of Orthopaedic Surgery and Computer Assisted Surgery Center, Hospital for Special Surgery, Weill Medical College of Cornell University, 535 East 70th St, New York, NY 10021, USA

2 Department of Orthopaedic Surgery, Spaarne Gasthuis, Hoofddorp, The Netherlands
3 Department of Orthopaedic Surgery, Noordwest Ziekenhuisgroep, Alkmaar, The Netherlands

4 Department of Orthopedic Surgery, Amsterdam Movement Sciences (AMS), Amsterdam University Medical Centers, Amsterdam, The Netherlands 


\section{Introduction}

Unicompartmental knee arthroplasty (UKA) is a well-established treatment for patients with isolated compartmental knee arthritis. Advantages of UKA over total knee arthroplasty (TKA) include reduced morbidity and mortality, preservation of normal knee kinematics and faster recovery [35, 49, 59]. However, national registry data have shown lower revision rates after TKA in comparison to UKA $[49,66]$. Reasons for UKA revision include aseptic loosening, malalignment, progression of osteoarthritis, instability, infection and periprosthetic fractures $[49,66]$.

Periprosthetic fractures represent a complex complication with serious consequences in UKA and have been associated with increased mortality and morbidity [26]. The periprosthetic fractures in UKA are most commonly reported on the tibial side (approximately 87\%) [66]. Although these periprosthetic tibial fractures are relatively rare compared to other complications in UKA, recent registry-based studies have shown an increased rate of periprosthetic fractures in cementless UKAs compared to cemented UKAs $[49,63]$. Since the interest of cementless fixation for UKAs is expected to increase, the rate of periprosthetic fractures may increase as well [49, 63]. However, registry-based studies may not provide reliable information about all fractures, as some periprosthetic fractures are internally fixed and the components are not revised or are treated conservatively. Another common limitation of registry-based studies is that tibial and femoral periprosthetic fractures are not reported separately. This stresses the need for a thorough evaluation of the incidence of periprosthetic tibial fractures in cemented and cementless UKAs using clinical studies. Furthermore, there is a lack of studies providing an overview of the available evidence on characteristics and risk factors of periprosthetic tibial fractures in UKA to gain a better understanding and awareness.

Therefore, the primary study aim was to estimate the incidence of periprosthetic tibial fractures in cemented and cementless UKA using clinical studies. Secondarily, relevant studies were systematically reviewed to summarize characteristics and risk factors of periprosthetic tibial fractures in UKA. Based on earlier large case series of both cemented and cementless UKAs reporting no non-traumatic periprosthetic tibial fractures $[62,68]$, it was hypothesized that comparable low incidences of periprosthetic tibial fractures can be achieved as long as surgeons are aware of factors that could increase the risk.

\section{Methods}

\section{Search strategy}

This systematic review with meta-analysis was conducted according to the PRISMA guidelines [65]. Medline,
Cochrane and Embase databases were comprehensively searched on 28 May 2020. The database search included several combinations of key terms: "unicompartmental", "knee", "arthroplasty", "failure", "complication", "survival", "survivorship", "revision", "reoperation", "fracture" and "collapse". The search was, however, limited to English language studies published since 2000.

After duplicates were excluded, titles and abstracts were screened by two independent reviewers (*** \& ***). Subsequently, full texts of the potential studies were carefully assessed by the two reviewers to confirm study eligibility. To be eligible, the study needed to contain information on proportion, characteristics and/or risk factors of periprosthetic tibial fractures in UKA. Clinical studies with information on fixation type and proportion were used to estimate incidences. For information regarding characteristics and/or risk factors, any study design was considered eligible, including case reports and laboratory studies. Although case reports and laboratory studies constitute low-level evidence, a systematic review of such studies can provide a better understanding and awareness of tibial plateau fractures in UKA. Studies were excluded if they reported on bicompartmental UKAs, used the same database, were reviews, registry-based studies, commentaries or abstracts. References of the included studies were checked for any missing studies. Any disagreements on study eligibility were resolved through consultation of the third reviewer $(* * *)$.

\section{Data collection and analysis}

Data extraction was entered in predefined spreadsheets by two independent reviewers. First author, publication year and study design were reported for each study. Total number of UKAs, number of fractures and fixation type were collected only from clinical studies for the analysis of incidence. To identify potential risk factors, characteristics of patients with and without periprosthetic tibial fractures were collected from clinical studies and compared. For example, body mass index (BMI) of patients with and without fractures were compared. Both clinical studies and case reports were used to evaluate characteristics of periprosthetic tibial fractures (time of fracture in relation to UKA, fracture mechanism [traumatic or nontraumatic], fracture type, type of treatment). Time of fracture in relation to UKA was classified into the following time-points: during surgery, within 3 months postoperatively, between 4 and 12 months postoperatively and after 1 year postoperatively. Schematic drawings were used to present the fracture types found on available radiographs. Causes of fractures considered by authors from each study 
were evaluated and summarized. Finally, conclusions of laboratory studies were presented.

\section{Methodological quality assessment}

Different tools for methodological quality assessment were used depending on study design.

The National Institutes of Health (NIH) checklist was used for all clinical studies [67], The Case Report (CARE) checklist was used for case reports [29], and the Quality Appraisal for Cadaveric Studies (QUACS) checklist [90] was used for cadaveric studies. A score was provided for each article (poor, fair or good). The assessment was performed by two independent reviewers (*** \& ***) and disagreements of the level of study quality were resolved through consultation of the third reviewer $(* * *)$.

\section{Statistical analyses}

Incidence of periprosthetic tibial fractures was calculated as the number of fractures divided by the total number of UKAs from each clinical study. These data were combined via proportion meta-analysis [94]. This is a tool to calculate an overall proportion from studies reporting a single proportion. Combined proportions were determined for cementless and cemented UKAs. A subgroup analysis was performed for cementless and cemented Oxford Partial Knee Implants. Effect sizes and 95\% Confidence Intervals (CI) were determined using a random-effects model by the back-transformation of the weighted mean of the logit-transformed proportions with Dersimonian weights. Characteristics between patients with and without periprosthetic tibial fractures were compared using the chi-square test for categorical variables and independent $t$ test for continuous variables. All analyses were performed with $\mathrm{R}$ version 4.0.0 (R Foundation for Statistical Computing, Vienna, Austria).

\section{Results}

A total of 81 studies were included (Fig. 1). Fifty-eight (72\%) were clinical studies consisting of 30 retrospective case series (52\%) [1-6, 8-11, 14, 27, 31, 36, 37, 43-45, 47, $48,53,54,70,73,83,85,88,91,93,96], 14$ prospective case series $(26 \%)[7,17,18,32,51,55-58,61,77,78,86$, 95], seven retrospective cohort studies $(12 \%)[13,24,25$, $46,50,59,72]$, four prospective cohort studies (7\%) [28, 30,
$84,89]$ and three randomized controlled trials $(5 \%)[22,23$, $33]$. Ten (12\%) studies were case reports $[15,40,52,60,69$, $74,81,82,87,92]$. Thirteen (16\%) were laboratory studies, of which four (31\%) used sawbones [16, 20, 39, 64], four (31\%) finite element models $[41,42,75,76]$, three $(23 \%)$ human cadavers $[21,79,80]$ and two $(15 \%)$ a combination of finite element models with sawbones [19,71]. The quality of studies was considered to be good in 54 (67\%) studies, fair in $26(32 \%)$ studies, and poor in one (1\%) study. Table 1 summarizes the conclusions and quality assessment of the laboratory studies. Appendix 1 and 2 summarize the data extraction and quality assessment of the case reports and clinical studies, respectively.

\section{Incidence of fixation type}

The incidence of each fixation type was determined using 44 clinical studies $[1,3,5-10,17,18,22,23,28,30-33,36$, 43-46, 48, 50, 51, 53-59, 61, 70, 72, 73, 83-86, 89, 91, 93, 96], leading to a incidence of $1.24 \%$ (95\% CI $0.64-2.41$ ) for cementless and $1.58 \%$ (95\% CI 1.06-2.36) for cemented UKAs (Fig. 2). Subgroup analysis for the Oxford Partial Knee implants was performed using 21 clinical studies [1, $3,10,17,18,30,33,44,46,48,51,53-55,58,59,70,72$, $73,83,85,96]$, resulting in an incidence of $1.22 \%(95 \% \mathrm{CI}$ $0.60-2.49$ ) for cementless and $0.99 \%$ (95\% CI $0.62-1.59$ ) for cemented fixation (Fig. 3).

\section{Characteristics}

A total of 202 periprosthetic tibial fractures in UKA were reported in 58 clinical studies [1-4, 6-11, 13, 14, 17, 18, 22-25, 27, 28, 30-33, 36, 37, 43-48, 50, 51, 53-59, 61, $70,72,73,77,78,83-86,88,89,91,93,95,96]$ and ten case reports $[15,40,52,60,69,74,81,82,87,92]$. The time of fracture was noted for 127 fractures. Twenty-three fractures (18\%) occurred during the operation, 68 (54\%) presented within 3 months postoperatively, 19 (15\%) presented between 4 and 12 months postoperatively, and 17 (13\%) presented after 1 year postoperatively. Fracture mechanism was reported for 113 fractures with 95 (84\%) being non-traumatic.

Twenty-one fractures (10\%) had good-quality radiographs to assess the location of the fracture line $[6,14,33,40,45$, $48,52,69,74,81,85,87,88,92]$. Schematic drawings of the different fracture types are displayed in Fig. 4. 
Fig. 1 Preferred Reporting Items for Systematic Reviews and Meta-Analyses flow diagram

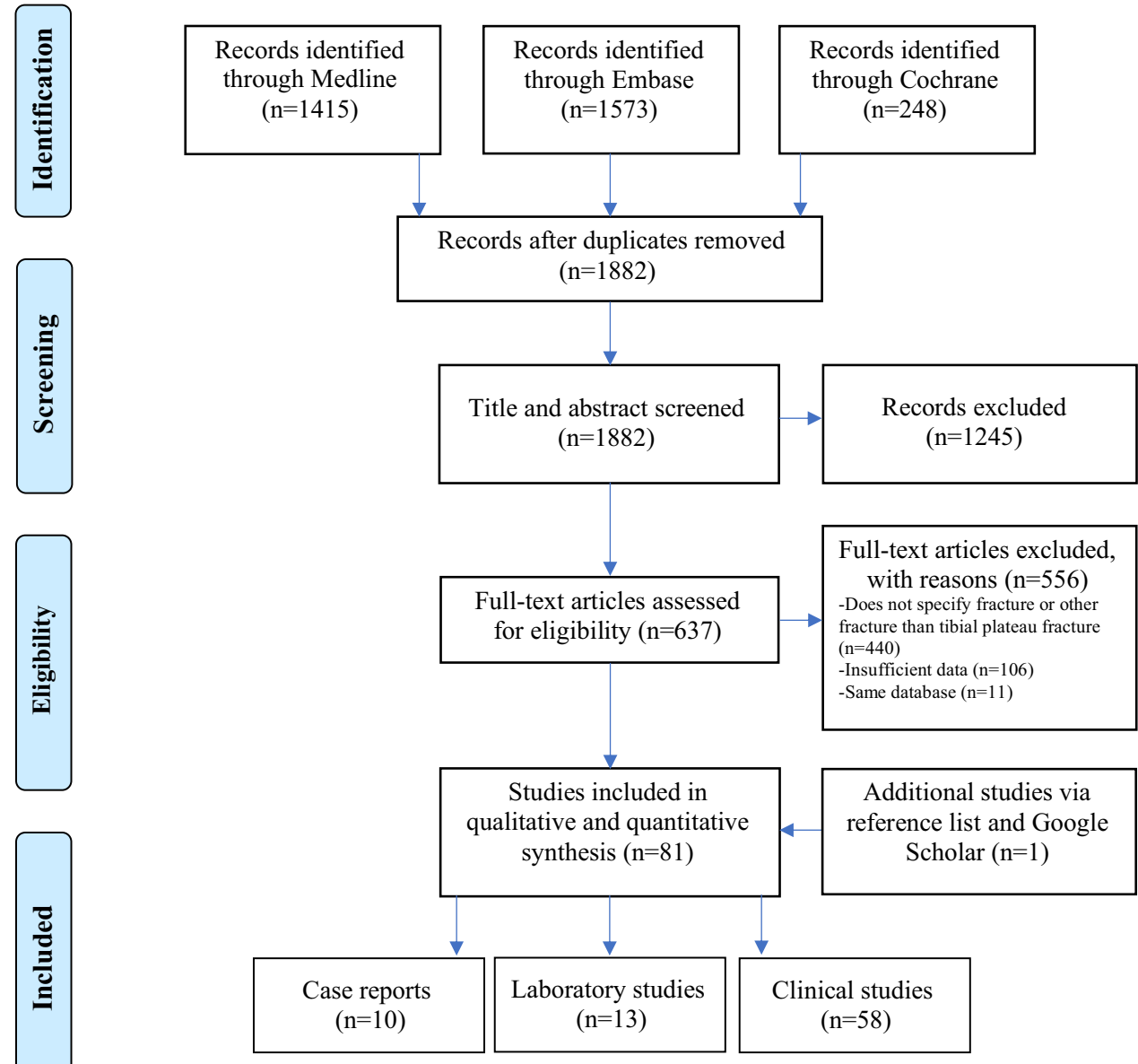

Based on information from 167 fractures, 85 (51\%) periprosthetic tibial fractures were treated with TKA (with metal augmentation and/or tibial stem extension), 38 (23\%) with ORIF, and 44 (26\%) with conservative treatment. Authors reported that eight fractures, initially treated conservatively, underwent a subsequent TKA; six fractures, initially treated with ORIF, underwent a subsequent TKA; one fracture, initially treated conservatively, underwent ORIF; and one fracture, initially treated conservatively, underwent ORIF and eventually needed a TKA.

\section{Risk factors}

Factors related to periprosthetic tibial fractures in UKA were analyzed using 23 clinical studies Table $2[1,8-10,13,18$,
23-25, 28, 31, 32, 37, 43, 47, 48, 57, 61, 86, 89, 91, 93, 96]. Fractures were associated with increased BMI $(p=0.017)$, advanced age $(p=0.003)$, decreased bone mineral density (BMD) $(p=0.030)$, female gender $(p=0.011)$, increased postoperative tibia-femoral alignment $(p=0.0120)$ and a very overhanging medial tibial condyle $(<0.001)$. The definition of a very overhanging medial tibial condyle was based on the medial eminence line (MEL) described by Yoshikawa et al. [96]. The MEL is a line drawn on preoperative radiographs, that is parallel to the tibial axis passing through the tip of medial intercondylar eminence. If this line passes medial to the medial cortex of the tibia, knees were classified as having a very overhanging medial tibial condyle. Fractures were not associated with the postoperative level of patient activity $(p=0.976)$ or with the tibial component alignment angle in the coronal plane $(p=0.130)$. 


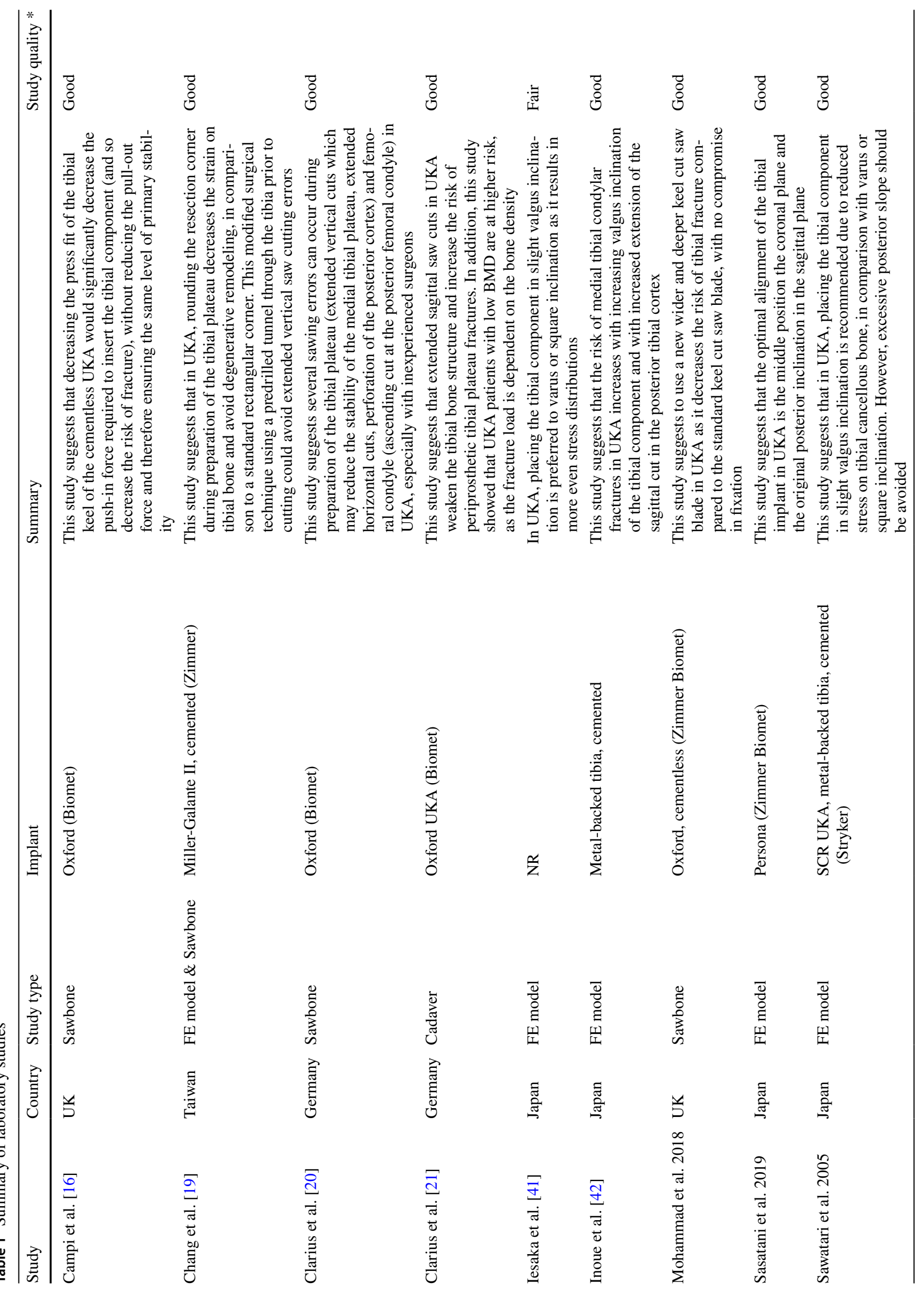




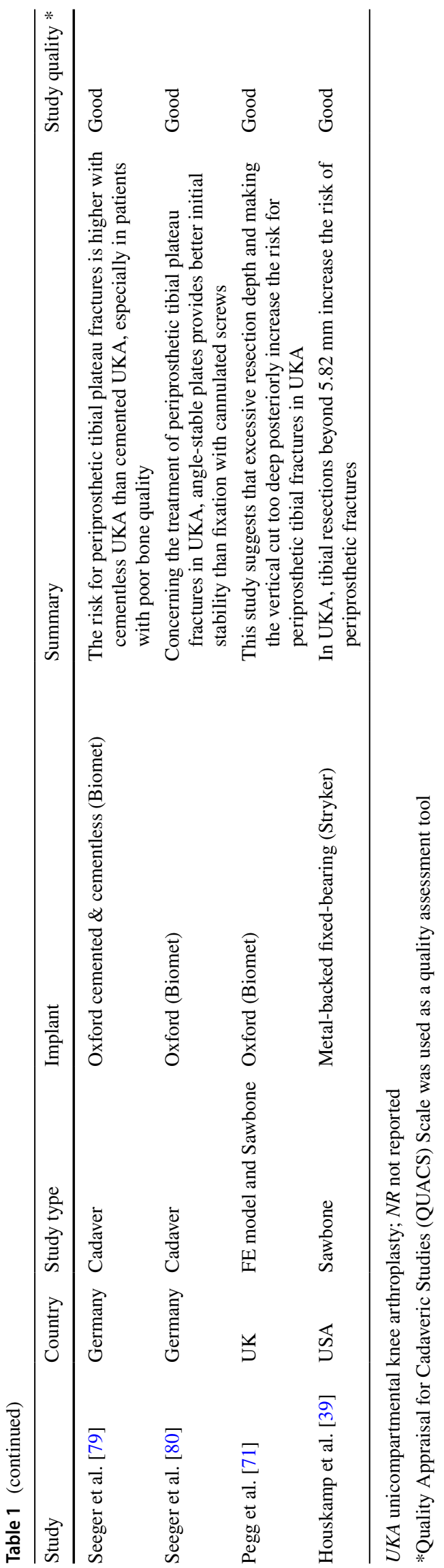

\section{Authors considerations}

Authors reported their considerations of cause of fracture in 36 clinical studies [1, 2, 4-11, 13, 14, 17, 18, 23, 30, 31, $33,36,37,43-45,54,55,57,61,70,84,85,88,89,91,93$, $95,96]$ and nine case reports $[15,40,52,60,69,74,81,82$, 87, 92] (Table 3).

\section{Discussion}

The main study finding was that the incidence of periprosthetic tibial fractures in cemented and cementless UKA was comparable. However, experimental evidence showed that excessive interference fit (press fit), excessive resection depth, making the sagittal cut too deep posteriorly, and low BMD reduces the load required for a periprosthetic tibial fracture to occur. Furthermore, clinical studies revealed that patients with fractures were more often female, of older age, exhibited higher BMI and postoperative alignment angles, had lower BMD and had very overhanging medial tibial condyles.

Contrarily to the main finding of this study, two recent registry-based studies showed higher rates of periprosthetic fractures in cementless compared to cemented Oxford Partial Knee implants [49, 63], raising some concerns regarding a keel design in cementless techniques. Campi et al. demonstrated that fixation of the cementless mobile-bearing Oxford UKA is ensured by the interference fit [18]. However, an excessive interference increases the assembly load required to push-in the component potentially introducing a splitting force during impaction (type V fracture) [16]. As this interference fit, combined with an impaction technique, could introduce an additional risk factor for fractures, the cementless Oxford Partial Knee implant may be less forgiving to surgical errors and patients who are at higher risk of periprosthetic tibial fractures.

Several surgical errors have been proposed by authors to cause periprosthetic tibial fractures in UKA Table (3). Only a few authors have supported their conclusion with experimental evidence. Laboratory studies showed a vertical saw cut too distal in the posterior tibial cortex and excessive tibial bone resection reduces the load required for a fracture to occur [20, 21, 39, 71]. Additionally, laboratory studies on the role of tibial component alignment suggested valgus alignment and an excessive posterior slope should be avoided [41, 42, 76]. Other authors based their conclusions on radiographic or intraoperative findings. Radiographs revealed that fracture lines went through multiple pinholes of the extramedullary tibial guide (type II fracture) [15]. One author reported that a fracture occurred due to breaching the posterior cortex while using a tibial gouge for keel preparation in Oxford Partial Knee implants (type V fracture) [82]. 
Fig. 2 Proportion meta-analysis to estimate the incidence of fractures in cemented (a) and cementless (b) unicompartmental knee arthroplasty a

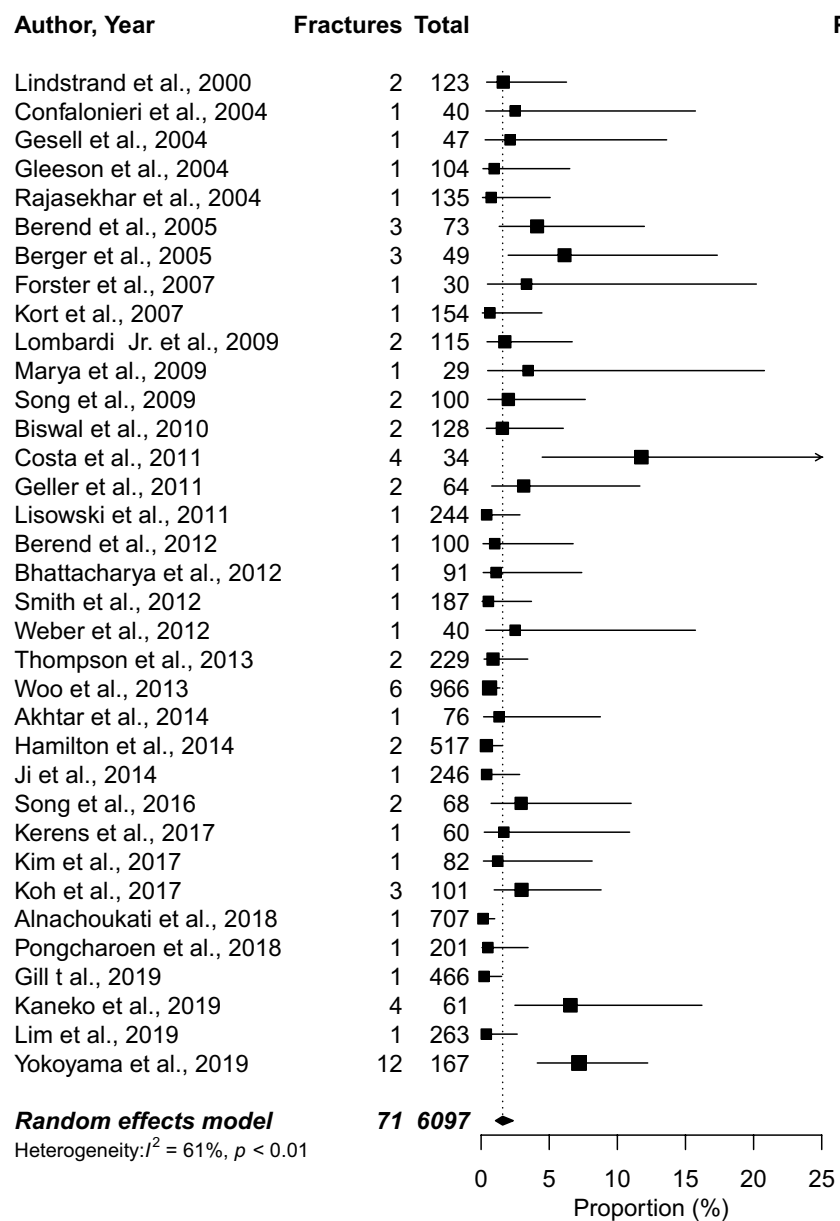

Proportion (\%) [95\% C.I.]

$1.63[0.41 ; 6.27]$

$2.50[0.35 ; 15.73]$

$2.13[0.30 ; 13.62]$

$0.96[0.14 ; 6.51]$

$0.74[0.10 ; 5.07]$

$4.11[1.33 ; 11.98]$

$6.12[1.99 ; 17.33]$

$3.33[0.47 ; 20.20]$

$0.65[0.09 ; 4.46]$

$1.74[0.44 ; 6.68]$

$3.45[0.48 ; 20.79]$

$2.00[0.50 ; 7.64]$

$1.56[0.39 ; 6.03]$

$11.76[4.49 ; 27.46]$

$3.12[0.78 ; 11.65]$

$0.41[0.06 ; 2.85]$

$1.00[0.14 ; 6.75]$

$1.10[0.15 ; 7.39]$

$0.53[0.08 ; 3.70]$

$2.50[0.35 ; 15.73]$

$0.87[0.22 ; 3.42]$

$0.62[0.28 ; 1.38]$

$1.32[0.19 ; 8.75]$

$0.39[0.10 ; 1.53]$

$0.41[0.06 ; 2.83]$

$2.94[0.74 ; 11.01]$

$1.67[0.23 ; 10.90]$

$1.22[0.17 ; 8.15]$

$2.97[0.96 ; 8.81]$

$0.14[0.02 ; 1.00]$

$0.50[0.07 ; 3.44]$

$0.21[0.03 ; 1.51]$

$6.56[2.48 ; 16.21]$

$0.38[0.05 ; 2.65]$

$7.19[4.13 ; 12.23]$

1.58 [1.06; 2.36]

b Author, Year

Fractures Total

Proportion (\%) [95\% C.I.]

Jeer et al., 2004

Liddle et al., 2013

Lecuire et al., 2014

Blaney et al., 2017

Kerens et al., 2017

Panzram et al., 2017

Campi et al., 2018

Campi et al., 2018

Leenders et al., 2018

Yoshikawa et al., 2020

Random effects model

Heterogeneity: $I^{2}=64 \%, p<0.01$

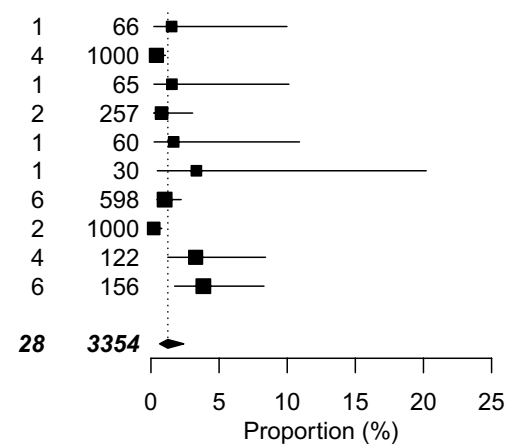

$1.52[0.21 ; 9.98]$

$0.40[0.15 ; 1.06]$

$1.54[0.22 ; 10.12]$

$0.78[0.19 ; 3.06]$

$1.67[0.23 ; 10.90]$

$3.33[0.47 ; 20.20]$

$1.00[0.45 ; 2.21]$

$0.20 \quad[0.05 ; 0.80]$

$3.28[1.24 ; 8.41]$

$3.85[1.74 ; 8.30]$

$1.24[0.64 ; 2.41]$
Furthermore, one fracture occurred after breaching the tibial cortex with the screw to fixate a cementless fixed-bearing UKA (type VI) [87]. These findings indicate that surgical actions that weaken cortical bone or reduce the bony area under the tibial component increase the risk of fracture.
However, more studies evaluating fractures under different conditions in UKA are necessary to understand the main pathologic elements of periprosthetic tibial fractures.

It was further noted that female gender, higher BMI and age, osteoporosis, excessive postoperative alignment 
Fig. 3 Proportion meta-analysis to estimate the incidence of fractures in cemented (a) and cementless (b) Oxford Partial Knee unicompartmental knee arthroplasty

\section{a

Author, Year
Gleeson et al., 2004
Rajasekhar et al., 2004
Kort et al., 2007
Lombardi Jr. et al., 2009
Song et al., 2009
Geller et al., 2011
Lisowski et al., 2011
Smith et al., 2012
Akhtar et al., 2014
Ji et al., 2014
Kerens et al., 2017
Kim et al., 2017
Alnachoukati et al., 2018
Pongcharoen et al., 2018
Random effects model
Heterogeneity. ${ }^{2}=0 \%, p=0.59$

\section{b Author, Year}

Liddle et al., 2013

Lecuire et al., 2014

Blaney et al., 2017

Kerens et al., 2017

Panzram et al., 2017

Campi et al., 2018

Campi et al., 2018

Leenders et al., 2018

Yoshikawa et al., 2020

Random effects model

Heterogeneity: $I^{2}=68 \%, p<0.01$

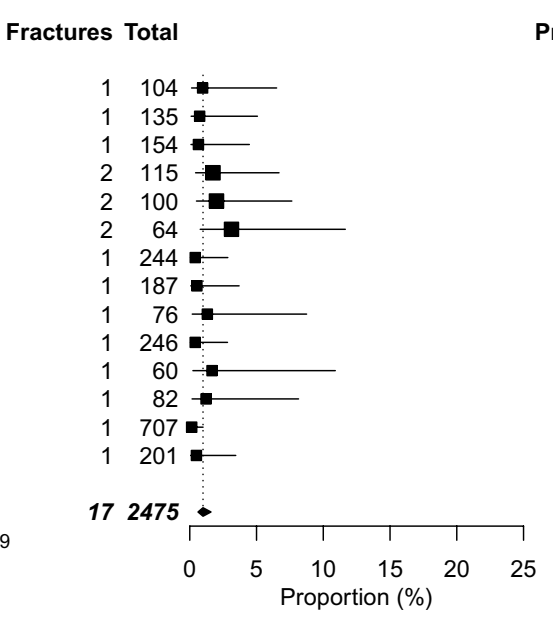

Proportion (\%) [95\% C.I.]

$0.96[0.14 ; 6.51]$

$0.74[0.10 ; 5.07]$

$0.65[0.09 ; 4.46]$

$1.74[0.44 ; 6.68]$

$2.00[0.50 ; 7.64]$

$3.12[0.78 ; 11.65]$

$0.41[0.06 ; 2.85]$

$0.53[0.08 ; 3.70]$

$1.32[0.19 ; 8.75]$

$0.41[0.06 ; 2.83]$

$1.67[0.23 ; 10.90]$

$1.22[0.17 ; 8.15]$

$0.14[0.02 ; 1.00]$

$0.50[0.07 ; 3.44]$

$0.99[0.62 ; 1.59]$

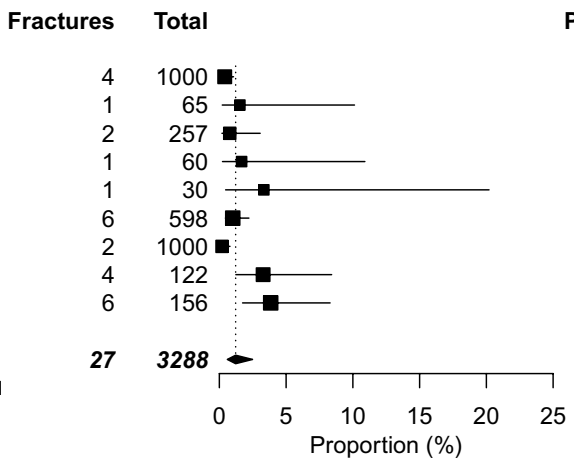

et al. showed a modified technique using a predrilled tunnel through the tibia prior to cutting could avoid extended vertical saw cut errors [19]. Campi et al. suggested the optimal interference fit for good implant stability and minimal risk of fracture is between $0.5 \mathrm{~mm}$ and $0.7 \mathrm{~mm}$ [16]. Mohammad et al. reported improvements in instrumentation that widen the keel slot could reduce the risk of tibial fractures in cementless Oxford Partial Knee implants without compromising fixation [64]. Some authors suggested to change the depth of the tibial keel in very small cementless Oxford Partial Knee components as the depth of the keel is currently the same in all components, increasing the risk of fracture [38]. Vardi et al. reported that a change was made to the shape and size of the tibial keel of the Alphanorm implant due to high rates of periprosthetic tibial fractures [88].

This study revealed that most of periprosthetic tibial fractures occurred intraoperatively or within 3 months of surgery and were non-traumatic. Studies of intraoperative fractures described that operative damage in combination with the impaction of the tibial component caused the tibial bone to fracture. The postoperative fractures within 3 months may be associated with operative damage and repetitive stress on the bone during daily activities such as walking and stair climbing. Fractures that presented after 3 months were mostly associated with traumatic events, excessive weight, mentation and implants can minimize fracture risk. Chang 


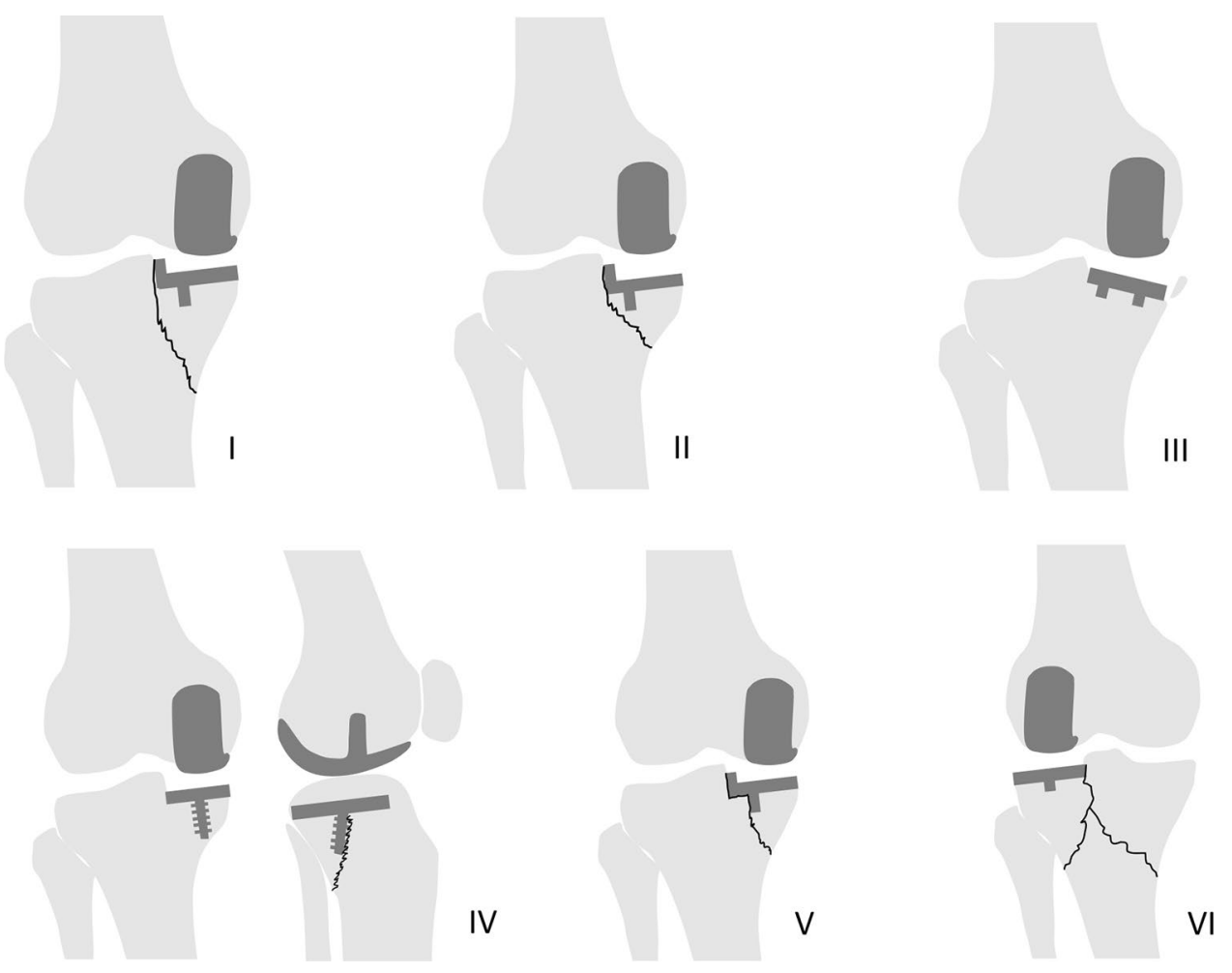

Fig. 4 Periprosthetic tibial fracture types in unicompartmetnal knee arthroplasty (UKA) seen on radiographs. I-II: Fracture line extending from the corner of the tibial resection to the medial cortex, resulting in a large (I) or small (II) medial plateau fracture. These fracture lines were identified on the anteroposterior (AP) view in patients with different implant designs. III: Varus subsidence or anterior subsidence of the tibia component, resulting in a small medial fragment fracture. These fractures were identified on the AP view. IV: Fracture line extending from the screw fixation to the posterior cortex, resulting in a posteromedial plateau fracture. The fracture line could not

osteoporosis, infection, all-polyethylene designs and tibial component malposition.

Furthermore, a classification of periprosthetic tibial fracture types was presented. As only $10 \%$ of all fractures could be used in the classification, the incidence and completeness of fracture types in UKA remain unknown. However, presented paths of fractures could explain the high-risk fracture regions. For example, the type I fracture not only suggest that an extended sagittal cut posteriorly can initiate a fracture, but indicate that risk of fracture propagation can be increased by placing pins from the extramedullary tibial guide within fracture line regions.

Some limitations of this study should be noted. First, the pooled estimated incidences of fractures were not adjusted for the follow-up period. However, almost all clinical studies had a minimum follow-up of one year and thus included the period when the majority of fractures occurred. Second, poor reporting on characteristics of fractures may have be identified on the AP view but only on the lateral view in a patient with a cementless fixed-bearing UKA with screw fixation. V: Fracture line extending from the tibial keel to the medial cortex, resulting in a medial plateau fracture. These fracture lines were identified on the AP view in patients with Oxford Partial Knee implants. VI: Two fracture lines extending from the corner of the tibial resection to the medial and lateral cortex after traumatic event six years postoperatively, resulting in a bicondylar plateau fracture. The fracture line was identified on the AP view in a patient with a lateral UKA

biased the results. Third, not all risk factors for fractures in UKA mentioned by authors have been verified with clinical data, and therefore might be subjective. Also, it cannot be clarified which risk factors verified with clinical data were independently related to periprosthetic tibial fractures as the findings were based on unadjusted analyses. Fourth, to analyze whether increased BMI and age were related to fracture cases, the weighted mean of the overall UKA population was used with the same standard deviation as those of the periprosthetic tibial fracture cases. Although this approach can be considered a fair approximation, the statistical difference for BMI and age between UKAs with and without fractures may have been underestimated. Finally, this study did not focus on the diagnostics and treatment of periprosthetic tibial fracture in UKA. However, based on the current search, three studies have currently evaluated the management of periprosthetic tibial fractures in UKA $[14,80,91]$. Treatments of the included fracture cases were reported 
Table 2 Results of the comparison between UKAs without and with fractures

\begin{tabular}{|c|c|c|c|c|c|}
\hline & $\begin{array}{l}\text { No. of clinical } \\
\text { studies }\end{array}$ & Group & No. of knees & Mean \pm SD or $\%$ & $P$ value $^{\S}$ \\
\hline \multirow[t]{2}{*}{ Body mass index $\left(\mathrm{kg} / \mathrm{m}^{2}\right)$} & \multirow[t]{2}{*}{4} & UKAs without fractures & 1379 & $26.3 \pm 6.8^{*}$ & \multirow[t]{2}{*}{0.017} \\
\hline & & UKAs with fractures & 12 & $31.0 \pm 6.8$ & \\
\hline \multirow[t]{2}{*}{ Age (yrs) } & \multirow[t]{2}{*}{14} & UKAs without fractures & 2701 & $64.4 \pm 9.2 *$ & \multirow[t]{2}{*}{0.003} \\
\hline & & UKAs with fractures & 24 & $70.0 \pm 9.2$ & \\
\hline \multirow[t]{2}{*}{ Bone mineral density $\left(\mathrm{g} / \mathrm{m}^{2}\right)$} & \multirow[t]{2}{*}{1} & UKAs without fractures & 155 & $0.73 \pm 0.10$ & \multirow[t]{2}{*}{0.030} \\
\hline & & UKAs with fractures & 12 & $0.65 \pm 0.16$ & \\
\hline \multirow[t]{2}{*}{ Tibial component angle $\left(^{\circ}\right)$} & \multirow[t]{2}{*}{1} & UKAs without fractures & 155 & $4.19 \pm 2.94$ & \multirow[t]{2}{*}{0.130} \\
\hline & & UKAs with fractures & 12 & $2.83 \pm 2.69$ & \\
\hline \multirow[t]{2}{*}{ Postoperative Tibia-femoral Angle $\left({ }^{\circ}\right)$} & \multirow[t]{2}{*}{1} & UKAs without fractures & 155 & $176.5 \pm 3.6$ & \multirow[t]{2}{*}{0.012} \\
\hline & & UKAs with fractures & 12 & $179.3 \pm 3.3$ & \\
\hline \multirow[t]{2}{*}{ Gender (Female/Male) } & \multirow[t]{2}{*}{20} & UKAs without fractures & 5910 & $67 \% / 33 \%$ & \multirow[t]{2}{*}{0.011} \\
\hline & & UKAs with fractures & 58 & $83 \% / 17 \%$ & \\
\hline \multirow[t]{2}{*}{ Activity level (High/Low) ${ }^{\#}$} & \multirow[t]{2}{*}{1} & UKAs without fractures & 566 & $20 \% / 80 \%$ & \multirow[t]{2}{*}{0.976} \\
\hline & & UKAs with fractures & 10 & $20 \% / 80 \%$ & \\
\hline \multirow[t]{2}{*}{ Very overhanging medial tibial condyle $(\mathrm{Yes} / \mathrm{No})^{\dagger}$} & \multirow[t]{2}{*}{1} & UKAs without fractures & 150 & $12 \% / 88 \%$ & \multirow[t]{2}{*}{$<0.001$} \\
\hline & & UKAs with fractures & 6 & $67 \% / 33 \%$ & \\
\hline
\end{tabular}

${ }^{\S}$ Chi square test was used for categorical variables and the independent $t$ test for continuous variables

"Patients with an UCLA (University of California Los Angeles) activity score $>6$ were classified as high

*The weighted mean of the overall UKA population with the same standard deviation as the tibial plateau fracture cases was used to allow for a fair comparison. This means this is an estimation and not the exact mean with standard deviation of the UKAs without fractures

${ }^{\dagger}$ Very overhanging medial tibial condyle was defined as a medial eminence line outside the medial cortex of the tibial shaft as described by Yoshikawa et al.[95]

Table 3 Factors associated with periprosthetic tibial fractures considered by authors

Implant and surgical factors

Excessive postoperative alignment angle

Pin placement (excessive pins, not predrilled, too close to medial tibial cortex)

Excessive tibial bone resection

Vertical saw cut too distal in posterior tibial cortex

Excessive posterior slope

Error in keel preparation

Learning curve/introduction of new implant

Limited instrumentation

Not enough medialization of the tibial component to tibial spine

Tibial peg hole drilled too deeply

All-polyethylene design

Tibial subsidence or collapse

Undersizing or oversizing of tibia component

Forceful impaction

\section{Patient factors}

Infection

Osteoporosis

Overweight

Small tibial size

Very overhanging medial tibial condyles

Trauma

\section{Rehabilitation factor}

Weightbearing too early to give a complete overview. Despite the aforementioned limitations, this is the first study evaluating the incidence of periprosthetic tibial fractures in cemented and cementless UKAs and providing an overview of the available evidence on periprosthetic tibial fracture in UKA.

\section{Conclusion}

The incidence of periprosthetic tibial fractures in cementless UKAs can be similar to those seen in cemented UKAs. However, surgeons should be aware that an excessive interference fit for cementless UKAs in combination with an impaction technique may introduce an additional risk, and may, therefore, be less forgiving to surgical errors and patients who are at higher risk of periprosthetic tibial fractures. While findings of this study raise awareness about periprosthetic tibial fractures in UKA, this study also highlights the importance of improvements in instrumentation and implants to prevent periprosthetic tibial fractures in future practices.

\section{Appendix}

See Tables 4, 5 . 


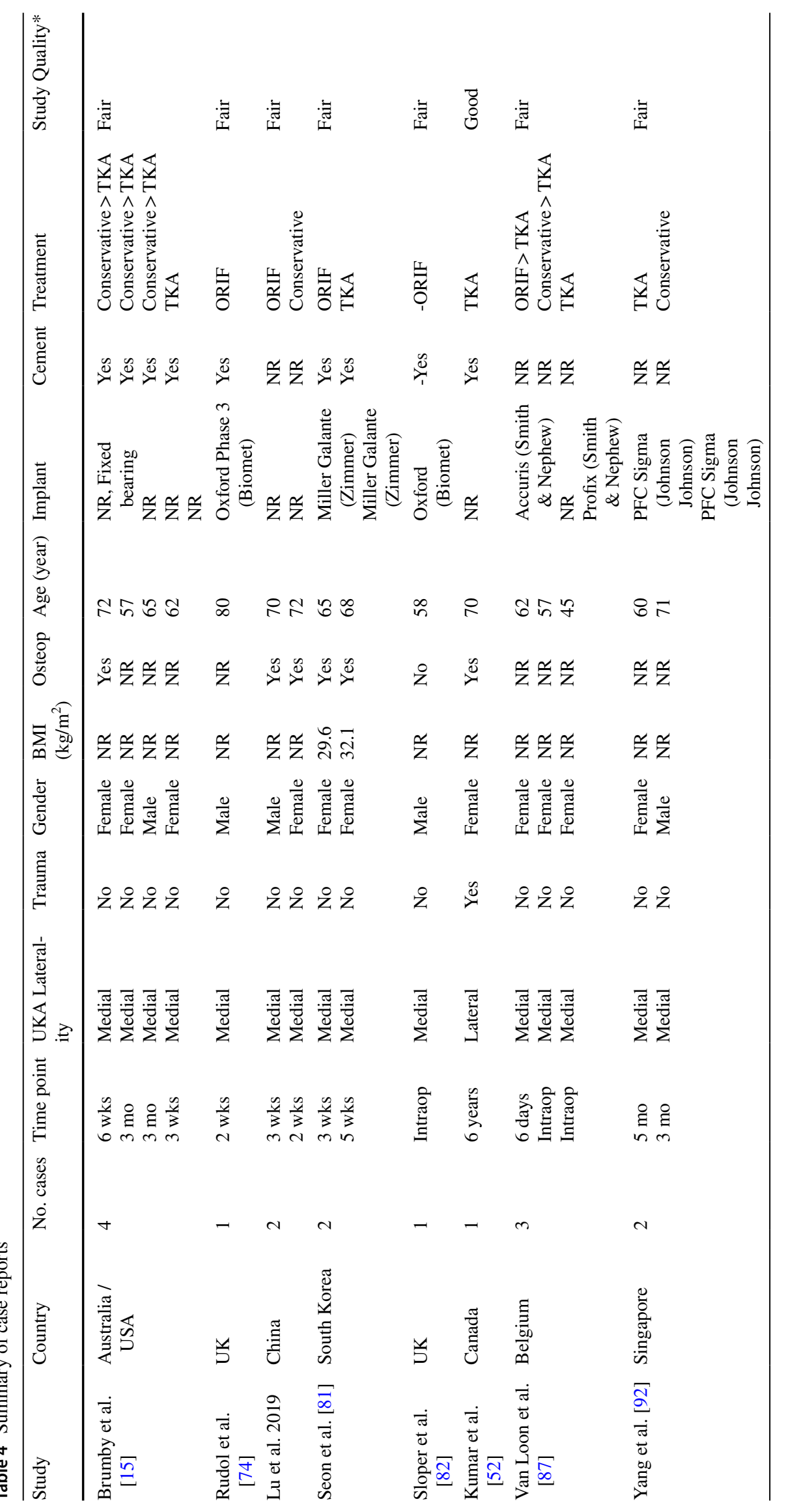




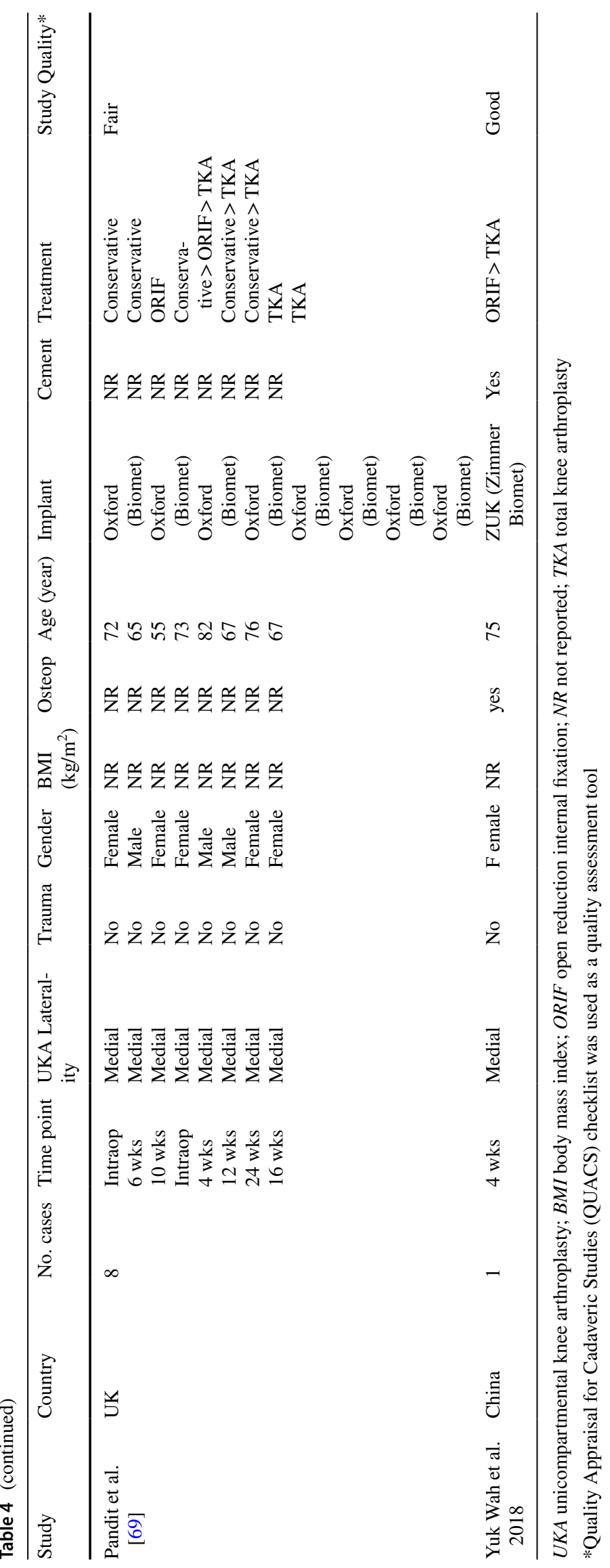




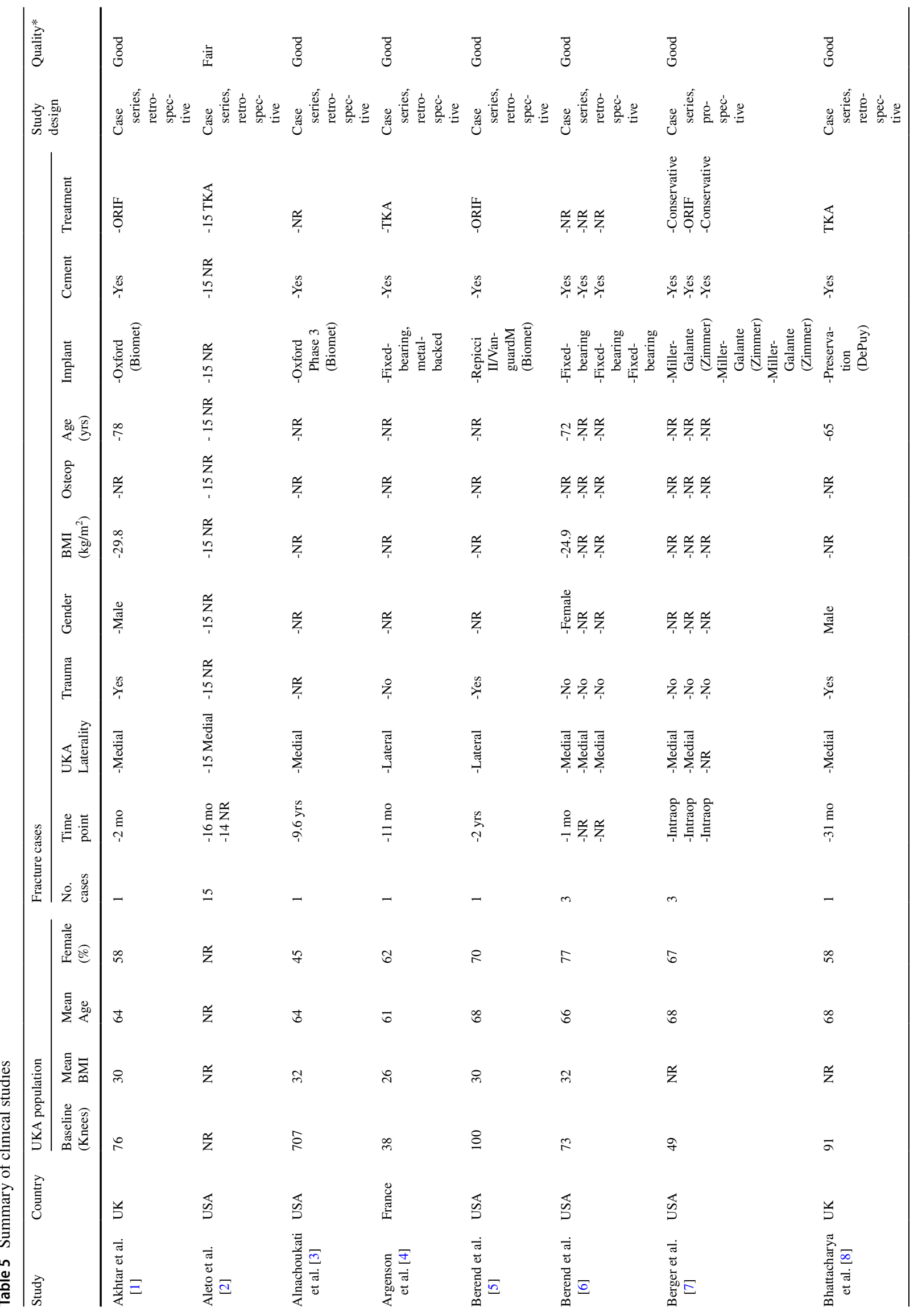




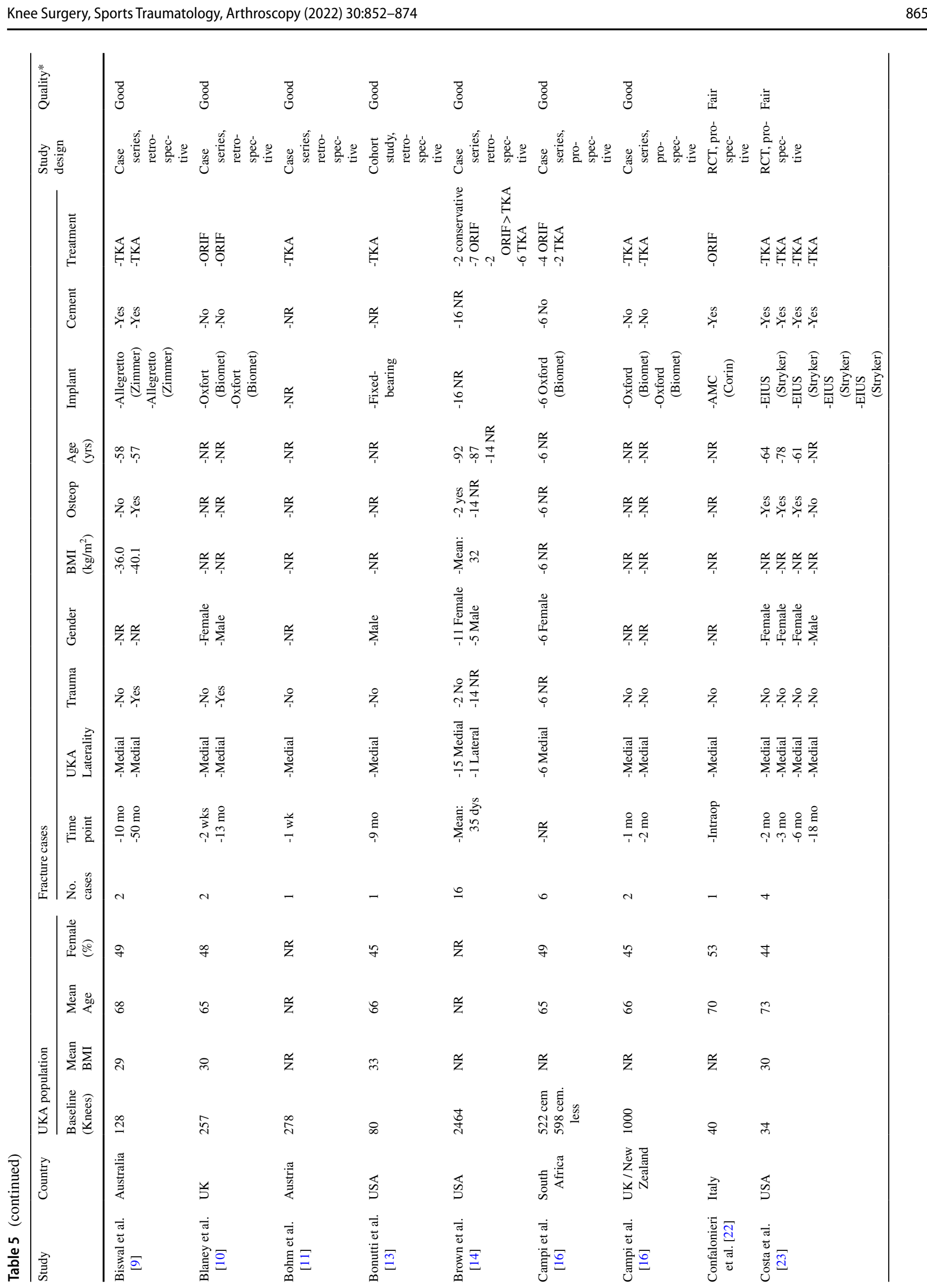

管 Springer 


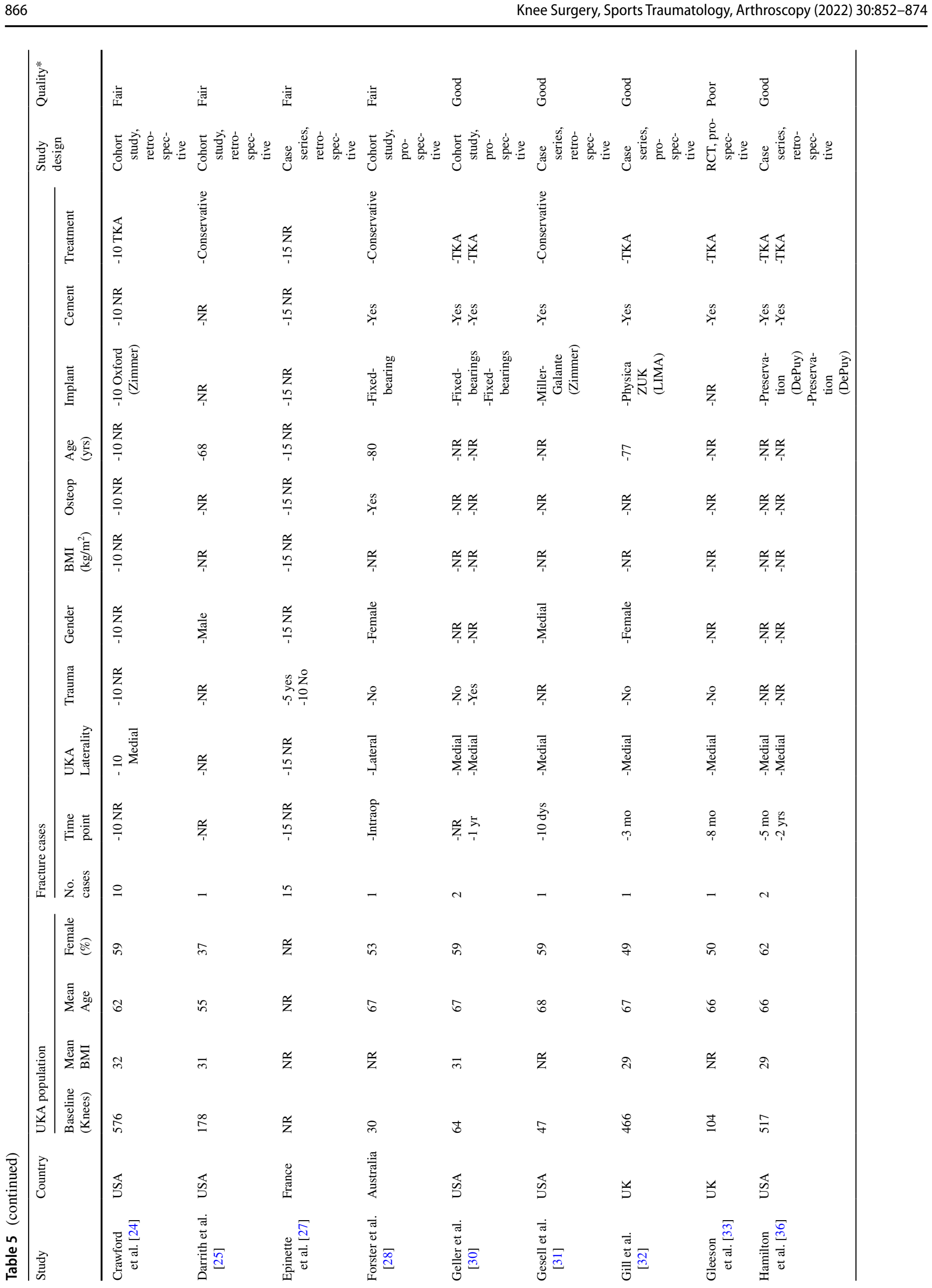

Springer 


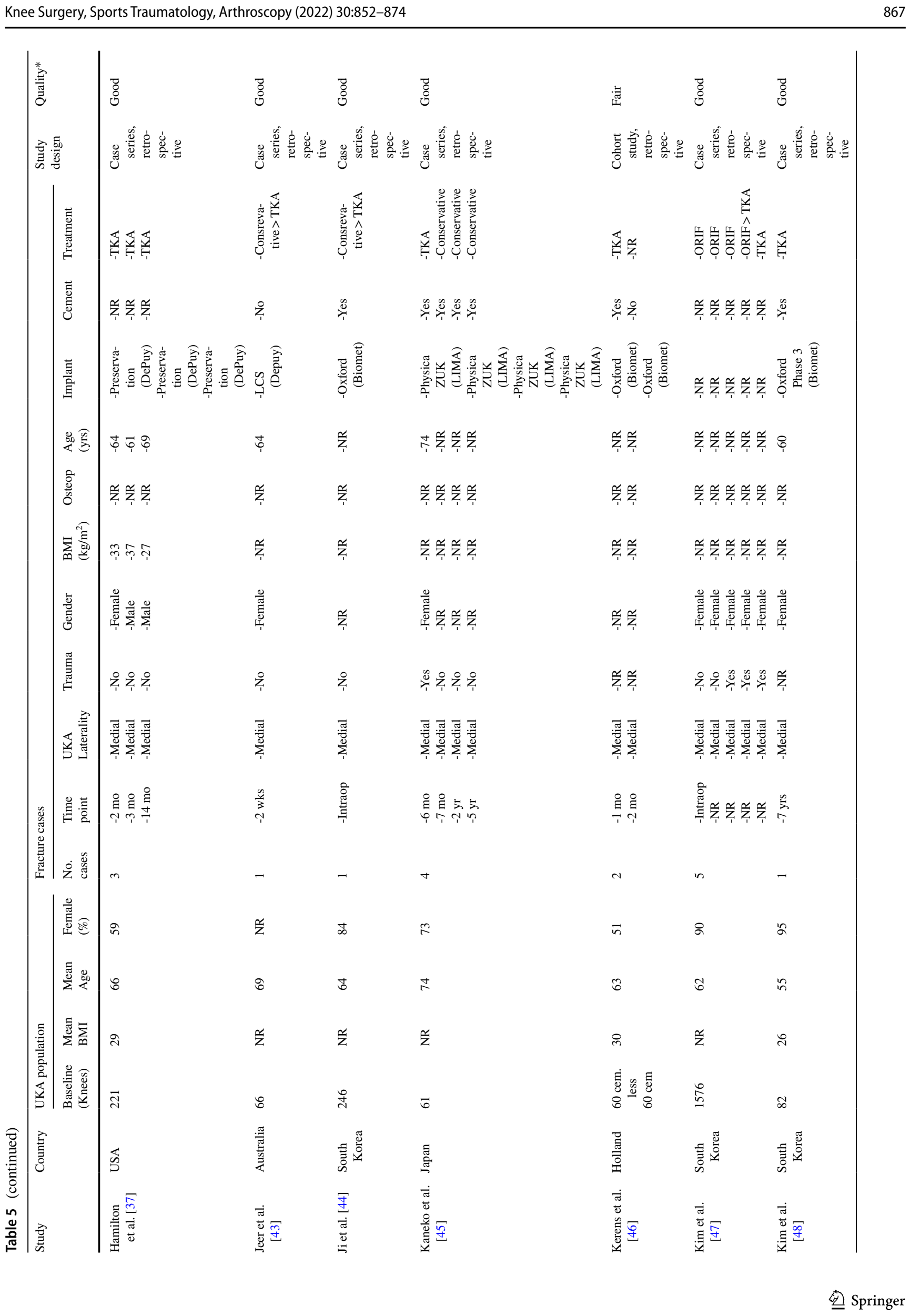




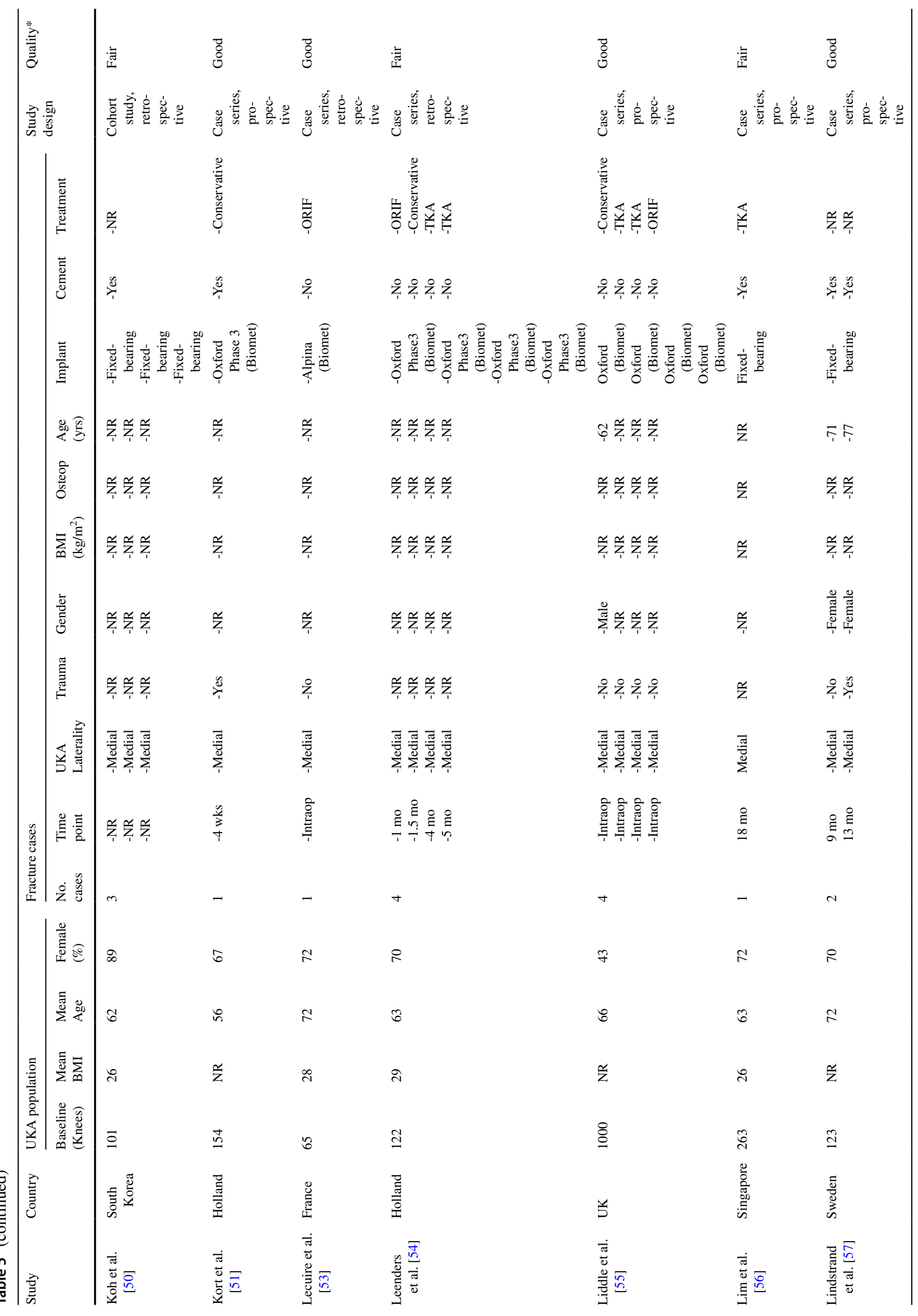




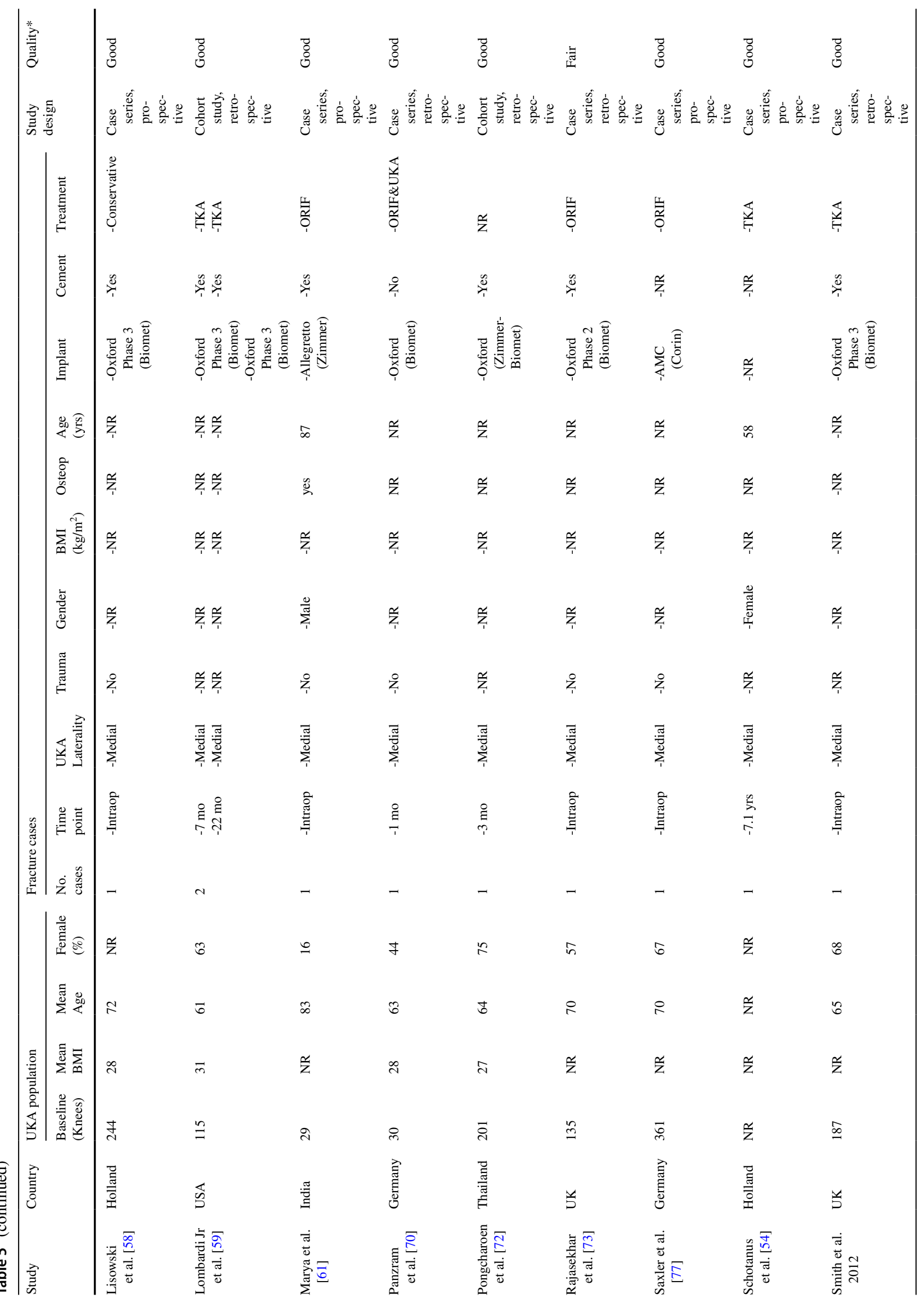




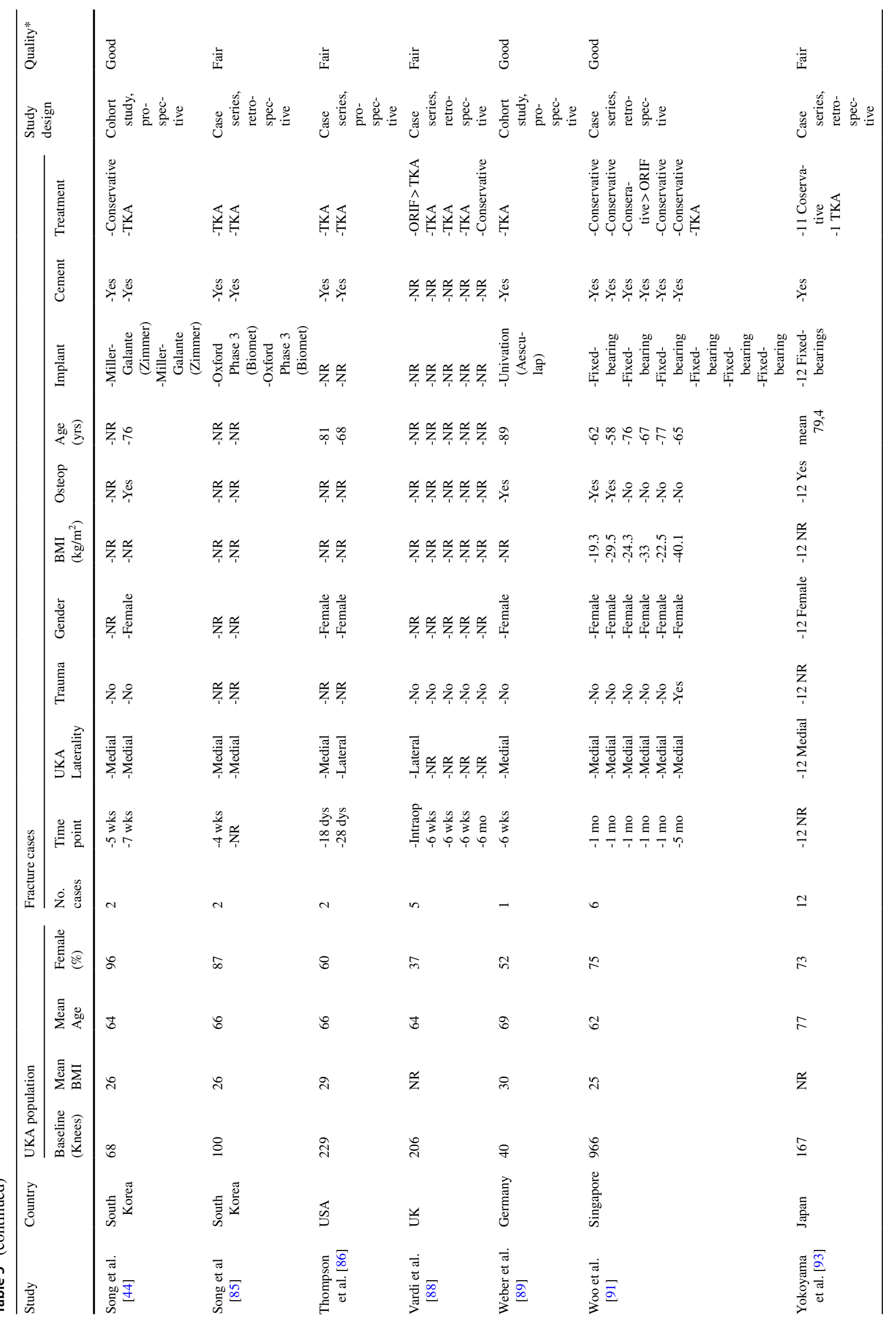




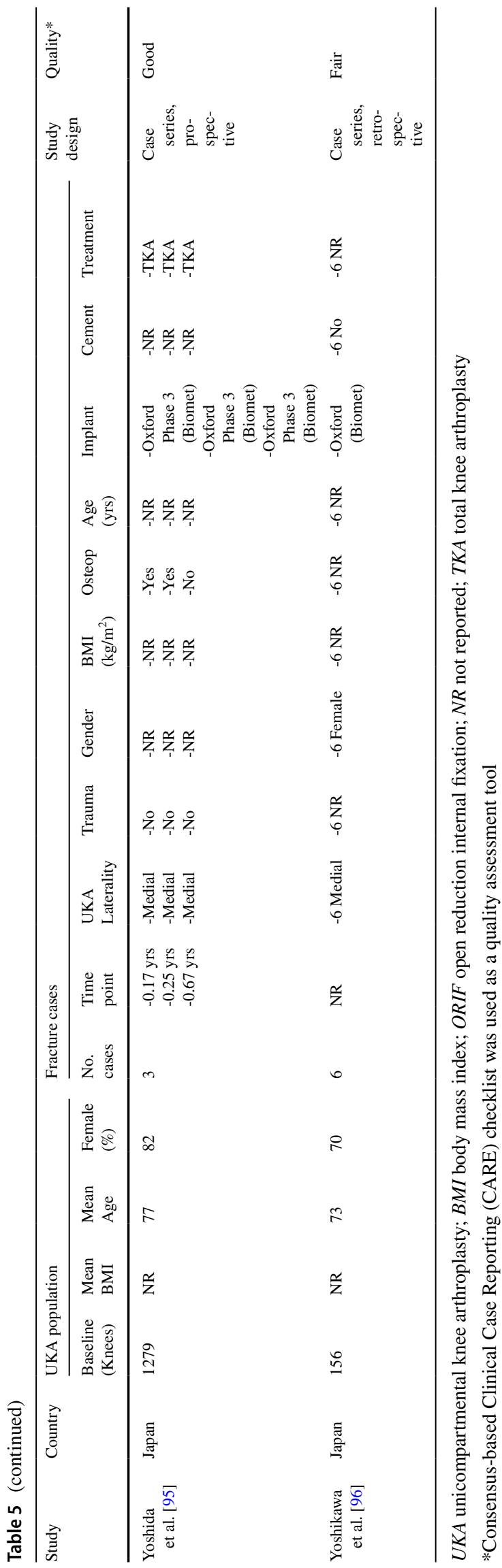

Author contributions JAB performed the literature search, scanned all abstracts and full texts, determined the quality of the studies and wrote the manuscript. TJ screened all abstracts, full texts and determined the quality of the studies as a second author and revised the manuscript. MSD checked data extraction, study quality and revised the manuscript. HAZ, GMMJK and ADP participated in the design of the study and revised manuscript. All authors read and approved the final manuscript.

Funding There is no funding source.

\section{Compliance with ethical standards}

Conflict of interest Author ADP report consultancy fees from Stryker (Mahwah, NJ, USA) and he has ownership interest in Engage Surgical (Orlando, FL, USA). The other authors (JAB, TJ, MSD, HAZ, GMMJK) report no conflict of interest.

Ethical approval This article does not contain any studies with human participants or animals performed by any of the authors.

Open Access This article is licensed under a Creative Commons Attribution 4.0 International License, which permits use, sharing, adaptation, distribution and reproduction in any medium or format, as long as you give appropriate credit to the original author(s) and the source, provide a link to the Creative Commons licence, and indicate if changes were made. The images or other third party material in this article are included in the article's Creative Commons licence, unless indicated otherwise in a credit line to the material. If material is not included in the article's Creative Commons licence and your intended use is not permitted by statutory regulation or exceeds the permitted use, you will need to obtain permission directly from the copyright holder. To view a copy of this licence, visit http://creativecommons.org/licenses/by/4.0/.

\section{References}

1. Akhtar KS, Somashekar N, Willis-Owen CA, Houlihan-Burne DG (2014) Clinical outcomes of bilateral single-stage unicompartmental knee arthroplasty. Knee 21:310-314

2. Aleto TJ, Berend ME, Ritter MA, Faris PM, Meneghini RM (2008) Early failure of unicompartmental knee arthroplasty leading to revision. J Arthroplasty 23:159-163

3. Alnachoukati OK, Barrington JW, Berend KR, Kolczun MC, Emerson RH, Lombardi AV Jr et al (2018) Eight hundred twentyfive medial mobile-bearing unicompartmental knee arthroplasties: the first 10-Year US multi-center survival analysis. J Arthroplasty 33:677-683

4. Argenson JN, Parratte S, Bertani A, Flecher X, Aubaniac JM (2008) Long-term results with a lateral unicondylar replacement. Clin Orthop Relat Res 466:2686-2693

5. Berend KR, Kolczun MC 2nd, George JW Jr, Lombardi AV Jr (2012) Lateral unicompartmental knee arthroplasty through a lateral parapatellar approach has high early survivorship. Clin Orthop Relat Res 470:77-83

6. Berend KR, Lombardi AV Jr, Mallory TH, Adams JB, Groseth KL (2005) Early failure of minimally invasive unicompartmental knee arthroplasty is associated with obesity. Clin Orthop Relat Res 440:60-66

7. Berger RA, Meneghini RM, Jacobs JJ, Sheinkop MB, Della Valle CJ, Rosenberg AG et al (2005) Results of unicompartmental knee arthroplasty at a minimum of ten years of follow-up. J Bone Joint Surg Am 87:999-1006 
8. Bhattacharya R, Scott CE, Morris HE, Wade F, Nutton RW (2012) Survivorship and patient satisfaction of a fixed bearing unicompartmental knee arthroplasty incorporating an all-polyethylene tibial component. Knee 19:348-351

9. Biswal S, Brighton RW (2010) Results of unicompartmental knee arthroplasty with cemented, fixed-bearing prosthesis using minimally invasive surgery. J Arthroplasty 25:721-727

10. Blaney J, Harty H, Doran E, O'Brien S, Hill J, Dobie I et al (2017) Five-year clinical and radiological outcomes in 257 consecutive cementless Oxford medial unicompartmental knee arthroplasties. Bone Joint J 99:623-631

11. Bohm I, Landsiedl F (2000) Revision surgery after failed unicompartmental knee arthroplasty: a study of 35 cases. J Arthroplasty $15: 982-989$

12. Bonnick SL (2006) Osteoporosis in men and women. Clin Cornerstone 8:28-39

13. Bonutti PM, Goddard MS, Zywiel MG, Khanuja HS, Johnson AJ, Mont MA (2011) Outcomes of unicompartmental knee arthroplasty stratified by body mass index. J Arthroplasty 26:1149-1153

14. Brown NM, Engh G, Fricka K (2019) Periprosthetic fracture following partial knee arthroplasty. J Knee Surg 32:947-952

15. Brumby SA, Carrington R, Zayontz S, Reish T, Scott RD (2003) Tibial plateau stress fracture. J Arthroplasty 18:809-812

16. Campi S, Mellon SJ, Ridley D, Foulke B, Dodd CAF, Pandit HG et al (2018) Optimal interference of the tibial component of the cementless Oxford Unicompartmental Knee Replacement. Bone Joint Res 7:226-231

17. Campi S, Pandit H, Hooper G, Snell D, Jenkins C, Dodd CAF et al (2018) Ten-year survival and seven-year functional results of cementless Oxford unicompartmental knee replacement: a prospective consecutive series of our first 1000 cases. Knee 25:1231-1237

18. Campi S, Pandit HG, Oosthuizen CR (2018) The Oxford medial unicompartmental knee arthroplasty: the South African experience. J Arthroplasty 33:1727-1731

19. Chang TW, Yang CT, Liu YL, Chen WC, Lin KJ, Lai YS et al (2011) Biomechanical evaluation of proximal tibial behavior following unicondylar knee arthroplasty: modified resected surface with corresponding surgical technique. Med Eng Phys 33:1175-1182

20. Clarius M, Aldinger PR, Bruckner T, Seeger JB (2009) Saw cuts in unicompartmental knee arthroplasty: an analysis of Sawbone preparations. Knee 16:314-316

21. Clarius M, Haas D, Aldinger PR, Jaeger S, Jakubowitz E, Seeger JB (2010) Periprosthetic tibial fractures in unicompartmental knee arthroplasty as a function of extended sagittal saw cuts: an experimental study. Knee 17:57-60

22. Confalonieri N, Manzotti A, Pullen C (2004) Comparison of a mobile with a fixed tibial bearing unicompartimental knee prosthesis: a prospective randomized trial using a dedicated outcome score. Knee 11:357-362

23. Costa CR, Johnson AJ, Mont MA, Bonutti PM (2011) Unicompartmental and total knee arthroplasty in the same patient. J Knee Surg 24:273-278

24. Crawford DA, Adams JB, Lombardi AV Jr, Berend KR (2019) Activity level does not affect survivorship of unicondylar knee arthroplasty at 5-year minimum follow-up. J Arthroplasty 34:1364-1368

25. Darrith B, Frisch NB, Tetreault MW, Fice MP, Culvern CN, Della Valle CJ (2019) Inpatient versus outpatient arthroplasty: a single-surgeon, matched cohort analysis of 90-day complications. J Arthroplasty 34:221-227

26. Della Rocca GJ, Leung KS, Pape HC (2011) Periprosthetic fractures: epidemiology and future projections. J Orthop Trauma 25:S66-70
27. Epinette JA, Brunschweiler B, Mertl P, Mole D, Cazenave A, French Society for H, et al (2012) Unicompartmental knee arthroplasty modes of failure: wear is not the main reason for failure: a multicentre study of 418 failed knees. Orthop Traumatol Surg Res 98:124-130

28. Forster MC, Bauze AJ, Keene GC (2007) Lateral unicompartmental knee replacement: fixed or mobile bearing? Knee Surg Sports Traumatol Arthrosc 15:1107-1111

29. Gagnier JJ, Kienle G, Altman DG, Moher D, Sox H, Riley D et al (2014) The CARE guidelines: consensus-based clinical case report guideline development. J Clin Epidemiol 67:46-51

30. Geller JA, Yoon RS, McKean J, Macaulay W (2011) Does a high-flexion design affect early outcome of medial unicondylar knee arthroplasty? Clinical comparison at 2 years. J Arthroplasty $26: 1468-1474$

31. Gesell MW, Tria AJ Jr (2004) MIS unicondylar knee arthroplasty: surgical approach and early results. Clin Orthop Relat Res 428:53-60

32. Gill JR, Nicolai P (2019) Clinical results and 12-year survivorship of the physica ZUK unicompartmental knee replacement. Knee 26:750-758

33. Gleeson RE, Evans R, Ackroyd CE, Webb J, Newman JH (2004) Fixed or mobile bearing unicompartmental knee replacement? a comparative cohort study. Knee 11:379-384

34. Grammens J, Van Haver A, Danckaers F, Booth B, Sijbers J, Verdonk P (2020) Small medial femoral condyle morphotype is associated with medial compartment degeneration and distinct morphological characteristics: a comparative pilot study. Knee Surg Sports Traumatol Arthrosc. https://doi.org/10.1007/s0016 7-020-06218-8

35. Gupta V, Kejriwal R, Frampton C (2020) Revision following cemented and uncemented Oxford-III primary medial unicompartmental knee replacements: a 19-Year analysis from the New Zealand joint registry. J Bone Joint Surg Am 102:1777-1783

36. Hamilton WG, Ammeen DJ, Hopper RH Jr (2014) Mid-term survivorship of minimally invasive unicompartmental arthroplasty with a fixed-bearing implant: revision rate and mechanisms of failure. J Arthroplasty 29:989-992

37. Hamilton WG, Collier MB, Tarabee E, McAuley JP, Engh CA Jr, Engh GA (2006) Incidence and reasons for reoperation after minimally invasive unicompartmental knee arthroplasty. J Arthroplasty 21:98-107

38. Hiranaka T, Yoshikawa R, Yoshida K, Michishita K, Nishimura T, Nitta $S$ et al (2020) Tibial shape and size predicts the risk of tibial plateau fracture after cementless unicompartmental knee arthroplasty in Japanese patients. Bone Joint J 102:861-867

39. Houskamp DJ, Tompane T, Barlow BT (2020) What is the critical tibial resection depth during unicompartmental knee arthroplasty? A biomechanical study of fracture risk. J Arthroplasty. https://doi.org/10.1016/j.arth.2020.04.005

40. Hung Y-W, Chi-Ho Fan J, Ka-Bon Kwok C, Lok-Fai Wong E, Ka-Man Lo C (2018) Delayed tibial-platform periprosthetic stress fracture after unicompartmental knee arthroplasty: uncommon and devastating complication. J Orthop Trauma Rehabilitation 25:29-33

41. Iesaka K, Tsumura H, Sonoda H, Sawatari T, Takasita M, Torisu $\mathrm{T}$ (2002) The effects of tibial component inclination on bone stress after unicompartmental knee arthroplasty. J Biomech 35:969-974

42. Inoue S, Akagi M, Asada S, Mori S, Zaima H, Hashida M (2016) The valgus inclination of the tibial component increases the risk of medial tibial condylar fractures in unicompartmental knee arthroplasty. J Arthroplasty 31:2025-2030

43. Jeer PJ, Keene GC, Gill P (2004) Unicompartmental knee arthroplasty: an intermediate report of survivorship after the introduction of a new system with analysis of failures. Knee 11:369-374 
44. Ji JH, Park SE, Song IS, Kang H, Ha JY, Jeong JJ (2014) Complications of medial unicompartmental knee arthroplasty. Clin Orthop Surg 6:365-372

45. Kaneko T, Kono N, Sunakawa T, Okuno Y, Ikegami H, Musha Y (2019) Reliable patient-reported outcome measure and survivorship of UKA for primary spontaneous osteonecrosis. Eur J Orthop Surg Traumatol 29:119-124

46. Kerens B, Schotanus MGM, Boonen B, Boog P, Emans PJ, Lacroix $\mathrm{H}$ et al (2017) Cementless versus cemented Oxford unicompartmental knee arthroplasty: early results of a non-designer user group. Knee Surg Sports Traumatol Arthrosc 25:703-709

47. Kim KT, Lee S, Lee JI, Kim JW (2016) Analysis and treatment of complications after unicompartmental knee arthroplasty. Knee Surg Relat Res 28:46-54

48. Kim YJ, Kim BH, Yoo SH, Kang SW, Kwack CH, Song MH (2017) Mid-Term results of Oxford medial unicompartmental knee arthroplasty in young asian patients less than 60 years of age: a minimum 5-year follow-up. Knee Surg Relat Res 29:122-128

49. Knifsund J, Reito A, Haapakoski J, Niinimaki T, Eskelinen A, Leskinen J et al (2019) Short-term survival of cementless Oxford unicondylar knee arthroplasty based on the finnish arthroplasty register. Knee 26:768-773

50. Koh IJ, Suhl KH, Kim MW, Kim MS, Choi KY, In Y (2017) Use of all-polyethylene tibial components in unicompartmental knee arthroplasty increases the risk of early failure. J Knee Surg 30:807-815

51. Kort NP, van Raay JJ, Cheung J, Jolink C, Deutman R (2007) Analysis of Oxford medial unicompartmental knee replacement using the minimally invasive technique in patients aged 60 and above: an independent prospective series. Knee Surg Sports Traumatol Arthrosc 15:1331-1334

52. Kumar A, Chambers I, Wong P (2008) Periprosthetic fracture of the proximal tibia after lateral unicompartmental knee arthroplasty. J Arthroplasty 23:615-618

53. Lecuire F, Berard JB, Martres S (2014) Minimum 10-year followup results of ALPINA cementless hydroxyapatite-coated anatomic unicompartmental knee arthroplasty. Eur J Orthop Surg Traumatol 24:385-394

54. Leenders AM, Schotanus MGM, Wind RJP, Borghans RAP, Kort NP (2018) A high rate of tibial plateau fractures after early experience with patient-specific instrumentation for unicompartmental knee arthroplasties. Knee Surg Sports Traumatol Arthrosc 26:3491-3498

55. Liddle AD, Pandit H, O'Brien S, Doran E, Penny ID, Hooper GJ et al (2013) Cementless fixation in Oxford unicompartmental knee replacement: a multicentre study of 1000 knees. Bone Joint J 95:181-187

56. Lim JW, Chen JY, Chong HC, Pang HN, Tay DKJ, Chia SL et al (2019) Pre-existing patellofemoral disease does not affect 10-year survivorship in fixed bearing unicompartmental knee arthroplasty. Knee Surg Sports Traumatol Arthrosc 27:2030-2036

57. Lindstrand A, Stenstrom A, Ryd L, Toksvig-Larsen S (2000) The introduction period of unicompartmental knee arthroplasty is critical: a clinical, clinical multicentered, and radiostereometric study of 251 Duracon unicompartmental knee arthroplasties. J Arthroplasty 15:608-616

58. Lisowski LA, van den Bekerom MP, Pilot P, van Dijk CN, Lisowski AE (2011) Oxford Phase 3 unicompartmental knee arthroplasty: medium-term results of a minimally invasive surgical procedure. Knee Surg Sports Traumatol Arthrosc 19:277-284

59. Lombardi AV Jr, Berend KR, Walter CA, Aziz-Jacobo J, Cheney NA (2009) Is recovery faster for mobile-bearing unicompartmental than total knee arthroplasty? Clin Orthop Relat Res 467:1450-1457
60. Lu C, Ye G, Liu W, Wu H, Wu G, Chen J (2019) Tibial plateau fracture related to unicompartmental knee arthroplasty: two case reports and literature review. Medicine (Baltimore) 98:e17338

61. Marya S, Thukral R (2009) Unicompartmental knee arthroplasty for tricompartment osteoarthritis in octogenarians. Indian $\mathbf{J}$ Orthop 43:361-366

62. Mohammad HR, Kennedy JA, Mellon SJ, Judge A, Dodd CA, Murray DW (2020) Ten-year clinical and radiographic results of 1000 cementless Oxford unicompartmental knee replacements. Knee Surg Sports Traumatol Arthrosc 28:1479-1487

63. Mohammad HR, Matharu GS, Judge A, Murray DW (2020) Comparison of the 10-year outcomes of cemented and cementless unicompartmental knee replacements: data from the National Joint Registry for England, Wales, Northern Ireland and the Isle of Man. Acta Orthop 91:76-81

64. Mohammad HR, Matharu GS, Judge A, Murray DW (2020) New surgical instrumentation reduces the revision rate of unicompartmental knee replacement: a propensity score matched comparison of 15,906 knees from the National Joint Registry. Knee 27:993-1002

65. Moher D, Liberati A, Tetzlaff J, Altman DG, Group P (2009) Preferred reporting items for systematic reviews and meta-analyses: the PRISMA statement. PLoS Med 6:e1000097

66. New Zealand Arthroplasty Registry (2019) NZJR 20 Year Report. https://nzoa.org.nz/nzoa-joint-registry. (Accessed 10 Jan 2020)

67. NIH study quality assessment tool (2015). https://www.nhlbi.nih. gov/health-topics/study-quality-assessment-tools. (Accessed 17 Jul 2020)

68. Pandit H, Jenkins C, Gill HS, Barker K, Dodd CA, Murray DW (2011) Minimally invasive Oxford phase 3 unicompartmental knee replacement: results of 1000 cases. J Bone Joint Surg Br 93:198-204

69. Pandit H, Murray DW, Dodd CA, Deo S, Waite J, Goodfellow J et al (2007) Medial tibial plateau fracture and the Oxford unicompartmental knee. Orthopedics 30:28-31

70. Panzram B, Bertlich I, Reiner T, Walker T, Hagmann S, Gotterbarm T (2017) Cementless Oxford medial unicompartimental knee replacement: an independent series with a 5-year-follow-up. Arch Orthop Trauma Surg 137:1011-1017

71. Pegg EC, Walter J, D’Lima DD, Fregly BJ, Gill HS, Murray DW (2020) Minimising tibial fracture after unicompartmental knee replacement: a probabilistic finite element study. Clin Biomech 73:46-54

72. Pongcharoen B, Chanalithichai N (2018) Clinical outcomes of patients with residual medial osteophytes following mobile bearing unicompartmental knee arthroplasty. PLoS ONE 13:e0205469

73. Rajasekhar C, Das S, Smith A (2004) Unicompartmental knee arthroplasty. 2- to 12-year results in a community hospital. J Bone Joint Surg Br 86:983-985

74. Rudol G, Jackson MP, James SE (2007) Medial tibial plateau fracture complicating unicompartmental knee arthroplasty. J Arthroplasty $22: 148-150$

75. Sasatani K, Majima T, Murase K, Takeuchi N, Matsumoto T, Oshima Y et al (2020) Three-dimensional finite analysis of the optimal alignment of the tibial implant in unicompartmental knee arthroplasty. J Nippon Med Sch 87:60-65

76. Sawatari T, Tsumura H, Iesaka K, Furushiro Y, Torisu T (2005) Three-dimensional finite element analysis of unicompartmental knee arthroplasty-the influence of tibial component inclination. J Orthop Res 23:549-554

77. Saxler G, Temmen D, Bontemps G (2004) Medium-term results of the AMC-unicompartmental knee arthroplasty. Knee 11:349-355

78. Schotanus MGM, Thijs E, Boonen B, Kerens B, Jong B, Kort NP (2018) Revision of partial knee to total knee arthroplasty with 
use of patient-specific instruments results in acceptable femoral rotation. Knee Surg Sports Traumatol Arthrosc 26:1656-1661

79. Seeger JB, Haas D, Jager S, Rohner E, Tohtz S, Clarius M (2012) Extended sagittal saw cut significantly reduces fracture load in cementless unicompartmental knee arthroplasty compared to cemented tibia plateaus: an experimental cadaver study. Knee Surg Sports Traumatol Arthrosc 20:1087-1091

80. Seeger JB, Jaeger S, Rohner E, Dierkes H, Wassilew G, Clarius M (2013) Treatment of periprosthetic tibial plateau fractures in unicompartmental knee arthroplasty: plates versus cannulated screws. Arch Orthop Trauma Surg 133:253-257

81. Seon JK, Song EK, Yoon TR, Seo HY, Cho SG (2007) Tibial plateau stress fracture after unicondylar knee arthroplasty using a navigation system: two case reports. Knee Surg Sports Traumatol Arthrosc 15:67-70

82. Sloper PJ, Hing CB, Donell ST, Glasgow MM (2003) Intra-operative tibial plateau fracture during unicompartmental knee replacement: a case report. Knee 10:367-369

83. Smith TO, Chester R, Glasgow MM, Donell ST (2011) Accelerated rehabilitation following Oxford unicompartmental knee arthroplasty: five-year results from an independent centre. Eur J Orthop Surg Traumatol 22:151-158

84. Song EK, Lee SH, Na BR, Seon JK (2016) Comparison of outcome and survival after unicompartmental knee arthroplasty between navigation and conventional techniques with an average 9-year follow-up. J Arthroplasty 31:395-400

85. Song MH, Kim BH, Ahn SJ, Yoo SH, Lee MS (2009) Early complications after minimally invasive mobile-bearing medial unicompartmental knee arthroplasty. J Arthroplasty 24:1281-1284

86. Thompson SA, Liabaud B, Nellans KW, Geller JA (2013) Factors associated with poor outcomes following unicompartmental knee arthroplasty: redefining the "classic" indications for surgery. J Arthroplasty 28:1561-1564

87. Van Loon P, de Munnynck B, Bellemans J (2006) Periprosthetic fracture of the tibial plateau after unicompartmental knee arthroplasty. Acta Orthop Belg 72:369-374

88. Vardi G, Strover AE (2004) Early complications of unicompartmental knee replacement: the Droitwich experience. Knee 11:389-394
89. Weber P, Utzschneider S, Sadoghi P, Pietschmann MF, Ficklscherer A, Jansson V et al (2012) Navigation in minimally invasive unicompartmental knee arthroplasty has no advantage in comparison to a conventional minimally invasive implantation. Arch Orthop Trauma Surg 132:281-288

90. Wilke J, Krause F, Niederer D, Engeroff T, Nurnberger F, Vogt L et al (2015) Appraising the methodological quality of cadaveric studies: validation of the QUACS scale. J Anat 226:440-446

91. Woo YL, Chin PL, Lo NN, Chia S-L, Tay DKJ, Yeo SJ (2013) Management of periprosthetic fracture in unicompartmental knee arthroplasty patients: a case series. Proc Singapore Health 22:267-272

92. Yang KY, Yeo SJ, Lo NN (2003) Stress fracture of the medial tibial plateau after minimally invasive unicompartmental knee arthroplasty: a report of 2 cases. J Arthroplasty 18:801-803

93. Yokoyama M, Nakamura Y, Egusa M, Doi H, Onishi T, Hirano $\mathrm{K}$ et al (2019) Factors related to stress fracture after unicompartmental knee arthroplasty. Asia Pac J Sports Med Arthrosc Rehabil Technol 15:1-5

94. Yoon BH, Park JW, Cha YH, Won SH, Lee YK, Ha YC et al (2020) Incidence of ceramic fracture in contemporary ceramicon-ceramic total hip arthroplasty: a meta-analysis of proportions. J Arthroplasty 35:1437-e1433

95. Yoshida K, Tada M, Yoshida H, Takei S, Fukuoka S, Nakamura $\mathrm{H}$ (2013) Oxford phase 3 unicompartmental knee arthroplasty in Japan-clinical results in greater than one thousand cases over ten years. J Arthroplasty 28:168-171

96. Yoshikawa R, Hiranaka T, Okamoto K, Fujishiro T, Hida Y, Kamenaga $T$ et al (2020) The medial eminence line for predicting tibial fracture risk after unicompartmental knee arthroplasty. Clin Orthop Surg 12:166-170

97. Yue B, Varadarajan KM, Ai S, Tang T, Rubash HE, Li G (2011) Differences of knee anthropometry between Chinese and white men and women. J Arthroplasty 26:124-130

Publisher's Note Springer Nature remains neutral with regard to jurisdictional claims in published maps and institutional affiliations. 